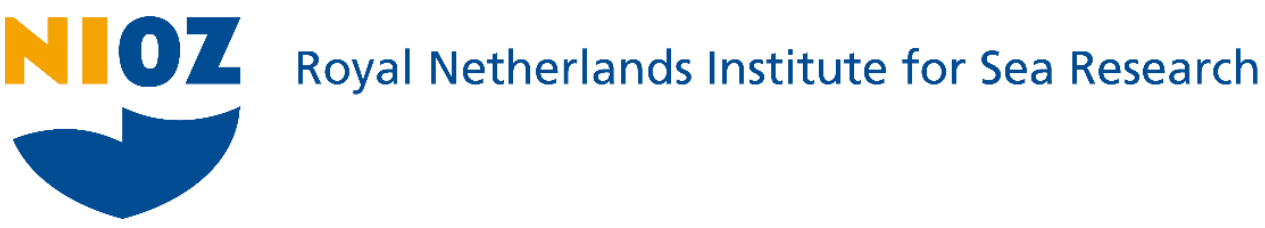

This is a pre-copyedited, author-produced version of an article accepted for publication, following peer review.

Grosse, J.; Brussaard, C.P.D. \& Boschker, H.T.S. (2019). Nutrient limitation driven dynamics of amino acids and fatty acids in coastal phytoplankton. Limnology and Oceanography, 64, 302-316

Published version: https://dx.doi.org/10.1002//no.11040

NIOZ Repository: http://www.vliz.be/nl/imis?module=ref\&refid=303624

[Article begins on next page]

The NIOZ Repository gives free access to the digital collection of the work of the Royal Netherlands Institute for Sea Research. This archive is managed according to the principles of the Open Access Movement, and the Open Archive Initiative. Each publication should be cited to its original source - please use the reference as presented.

When using parts of, or whole publications in your own work, permission from the author(s) or copyright holder(s) is always needed. 


\section{Nutrient limitation driven dynamics of amino acids and fatty acids in}

\section{2 coastal phytoplankton}

3 Julia Grosse $^{1 * \$}$, Corina P.D. Brussaard ${ }^{2}$ and Henricus T. S. Boschker ${ }^{1 \$}$

4

$5 \quad{ }^{1}$ Royal Netherlands Institute for Sea Research and Utrecht University, PO Box 140, 4400 AC

6 Yerseke, The Netherlands

$7 \quad{ }^{2}$ Royal Netherlands Institute for Sea Research and Utrecht University, PO Box 59, 1790 AB Den

8 Burg, Texel, The Netherlands

$9{ }^{\S}$ present address: Department of Biological Oceanography, GEOMAR Helmholtz Centre of Ocean

10 Research Kiel, Kiel, Germany

11 \$ present address: Department of Biotechnology, Delft University of Technology, Delft, The

12 Netherlands

13

14 *Corresponding author: jgrosse @ geomar.de

15 Keywords: nutrient limitation, fatty acids, amino acids, food quality, phytoplankton 16

17 Running head: Compound synthesis under $\mathrm{N}$ and $\mathrm{P}$ limitation 


\section{Compound synthesis under N/P limitation}

18

\section{Abstract}

Coastal seas like the North Sea have been subject to major changes in nutrient inputs over the last decades, resulting in shifts of limiting nutrients for phytoplankton communities. Here we investigated the seasonal and spatial distribution and synthesis patterns of individual amino acids and distinct fatty acid groups and show how these were affected by different nutrient limitations in natural coastal phytoplankton communities. Nitrogen limited communities exhibited substantially slower synthesis of essential amino acids compared to synthesis of non-essential amino acids. In short-term nutrient addition experiments this trend was reversed immediately after $\mathrm{N}$ addition to levels found under not limiting conditions. On the contrary, phosphorus limited communities showed no such shift in amino acids. Both $\mathrm{N}$ and $\mathrm{P}$ limitation induced a shift from structural to storage fatty acids with a concurrent decrease in the synthesis of poly-unsaturated fatty acids.

Reversed effects in fatty acid synthesis after $\mathrm{N}$ or $\mathrm{P}$ addition were only apparent after $72 \mathrm{~h}$, when they could be found in both fatty acid biosynthesis and concentrations. The different strategies of qualitative and quantitative regulation of different biomolecule synthesis under nutrient scarcity may have far-reaching consequences for the phytoplankton's nutritional value. Higher trophic levels may have to cope with the loss of essential amino acids and poly-unsaturated fatty acids in nutrient limited phytoplankton, which could induce changes in the structure of food webs. 


\section{Introduction}

Phytoplankton are main contributors to global primary production (Field et al., 1998), are the

foundation of many marine food webs and the source of essential compounds for higher trophic

levels (Arts and Kohler, 2009). Long-term perturbations of nutrient deliveries from land, however,

led to eutrophication in many coastal seas, impacting phytoplankton community structure and productivity in unfavorable ways (e.g. Smith et al., 1999; Philippart et al., 2000). In order to counteract repercussions of high nutrient loads the neighboring countries of coastal seas started to reduce nutrient loads in river systems. For example, members of the OSPAR Convention

(Oslo/Paris Convention for the Protection of the Marine Environment of the North-East Atlantic)

agreed to reduce inputs of riverine nitrogen $(\mathrm{N})$ and phosphorus $(\mathrm{P})$ to the North Sea by at least $50 \%$ compared to the year 1985 (OSPAR, 1988). Overall, nutrient reduction efforts were more effective for P removal compared to $\mathrm{N}$ removal (OSPAR, 2010; Troost et al., 2014) and resulted in drastic changes in nutrient availabilities, both of concentrations and relative ratios of dissolved inorganic $\mathrm{N}$ and $\mathrm{P}$ (DIN:DIP). Growing evidence suggests that $\mathrm{P}$ limitation is becoming more and more dominant in river influenced coastal areas such as the North Sea, the Gulf of Mexico or the South China Sea (Sylvan et al., 2007; Xu et al., 2008; Burson et al., 2016), thereby challenging the classical view, which considers $\mathrm{N}$ to be limiting in marine systems (Blomqvist et al., 2004; Howarth and Marino, 2006).

Changes in nutrient availability translate into changes in $\mathrm{C}: \mathrm{N}: \mathrm{P}$ ratios of phytoplankton biomass (Vrede et al., 2004; Diez et al., 2013), which can also be used as a tool to evaluate the nutritional quality of phytoplankton for higher trophic levels (Sterner and Elser, 2002). Looking closer, changes in $\mathrm{C}: \mathrm{N}: \mathrm{P}$ ratios illustrate shifts in the biomolecule composition. $\mathrm{C}: \mathrm{N}: \mathrm{P}$ requirements of major cellular biomolecules differ (Klausmeier et al., 2004); carbohydrates (CH) only contain C 
60 acids (FA), like carbohydrates, only contain $\mathrm{C}$ but they are found in complex membrane lipids that

61 often require $\mathrm{P}$ and/or N (Van Mooy et al., 2009).

62 Phytoplankton can adapt growth strategies to nutrient scarcity and increase or decrease 63 synthesis of different biomolecule groups. For example, synthesis of carbon rich storage 64 compounds, such as glucose or storage lipids, increases during nutrient limitation and leads to increased $\mathrm{C}: \mathrm{N}$ and $\mathrm{C}: \mathrm{P}$ ratios, which concurrently decreases food quality (Plath and Boersma, 2001; Borsheim et al., 2005). N:P ratios are affected as well (Geider and LaRoche, 2002; Quigg et al., 2003), however, the specific underlying dynamics in the synthesis of ribosomal RNA, pigments and proteins are difficult to investigate in phytoplankton cells and have so far mainly been demonstrated in computational model runs (Falkowski, 2000; Klausmeier et al., 2004; Arrigo, 2005).

$$
\text { However, technological advances, especially in liquid chromatography-isotopic ratio mass }
$$
spectrometry, make it now possible to obtain specific isotope information of a wide range of compounds and conduct synthesis rate measurements. Grosse et al. (2017) investigated the seasonal and spatial dynamics of concentrations and biosynthesis rates of total amino acids, storage fatty acids and carbohydrates as well as structural fatty acids and carbohydrates in North Sea phytoplankton communities. Results showed that nutrient limitation and season had large effects on the quantity of all biochemical classes, affecting both concentration and biosynthesis rates, e.g., AA concentration varied fourfold in concentration and up to eightfold in biosynthesis rates. The addition of the growth-limiting nutrient revealed an overall response in which storage compound synthesis decreased and AA synthesis was stimulated concurrently. Yet, the magnitude of response differed between limiting nutrients. While AA synthesis increased up to fivefold within $24 \mathrm{~h}$ upon the relief of $\mathrm{N}$ limitation, AA synthesis in $\mathrm{P}$ limited communities responded delayed and at a lower magnitude. And although separation of total FA and carbohydrates into 
84 storage and structural groups occurred in this study (based on polarity and glucose vs. all others 85 for $\mathrm{FA}$ and $\mathrm{CH}$, respectively) a specific evaluation is missing.

86 A compound specific evaluation would allow for a much more detailed assessment of food quality since several AA and FA are considered essential to higher trophic levels (Raubenheimer et al., 2009) and the availability of a single compound can affect zooplankton growth and reproduction (Müller-Navarra, 1995; Burns et al., 2011). Earlier studies show the effects of nutrient supply, light and temperature on FA dynamics in a wide range of phytoplankton groups (Renaud et al., 2002; Xin et al., 2010; Piepho et al., 2012). In general the limitation by nutrients causes an increase in triglycerides (non-polar/storage FA), and a concurrent decrease in membrane lipids (polar/ structural FA) especially under P-limitation (Fidalgo et al., 1998; Lynn et al., 2000). Additionally, the degree of FA saturation is also affected by nutrient shortage, causing a shift from poly-unsaturated FA (PUFA, which include essential FA) towards saturated FA (SFA; Siron et al., 1989; Reitan et al., 1994; Breteler et al., 2005). generally believed that the composition is relatively constant, an assumption mainly based on the geochemical composition in particulate organic carbon in the water column or from detrital matter

100 in surface sediments (Dauwe and Middelburg, 1998; Dauwe et al., 1999). This would suggest that 101 essential AA (EAA), which include amongst others phenylalanine (Phe), leucine (Leu), valine 102 (Val), and arginine (Arg, [see Fig. 1 for full list]) (Claybrook, 1983; Lin et al., 2015) are supplied at a constant ratio to non-essential AA (NEAA). EAA are, however, generally synthesized from non-essential pre-cursor AA and their synthesis require additional steps and enzyme reactions

105 (Fig. 1). Therefore, nutrient limitation can induce shifts in organelle composition (Arrigo, 2005), 106 and the up- or down-regulation of specific biomolecule pathways and their enzymes (Morey et al., 107 2011; Yang et al., 2011), which consequently could lead to the synthesis of different sets of 
108 proteins, with a possibly different composition of individual AA, and affect the nutritional quality

109 of phytoplankton.

110 Here we characterize nutrient driven dynamics in concentrations and biosynthesis rates of

111 individual AA and several FA groups (based on their degree of saturation and nutritional value to

112 higher trophic levels) obtained from the experiments by Grosse et al. (2017). We hypothesize that

$113 \mathrm{~N}$ and $\mathrm{P}$ availability or limitation affects the quality of AA and FA composition in phytoplankton.

114 Hence the short-term response to the relief of $\mathrm{N}$ and $\mathrm{P}$ limitation has different effects on individual

115 biomolecule synthesis rates. To address this hypothesis we evaluated the dynamics of individual

116 compounds in phytoplankton field populations during pre-bloom, spring bloom and post-bloom

117 conditions. Furthermore, we identified shifts in individual compound dynamics after the relief of

118 nutrient limitation in nutrient addition experiments $(24-72 \mathrm{~h})$ in order to determine nutrient-

119 specific and phytoplankton community-specific shifts in compound quality.

120

121

122

123

124

125

126

127

128

129

130

131

\section{Material and Methods}

Sampling transect. A total of five cruises spread over three consecutive years were conducted onboard the Dutch research vessel RV Pelagia, sampling a transect from the Dutch coast towards the center of the North Sea. Four stations (Fig. 2) with different nutrient settings were investigated. The coastal zone station $(\mathrm{CZ})$ is only $7 \mathrm{~km}$ offshore and influenced by high nutrient riverine runoff and its shallowness $(8 \mathrm{~m})$ assures a completely mixed water column. The Oyster Ground (OG) station is located around $100 \mathrm{~km}$ offshore and can be affected by either mixed coastal or stratified waters, depending on the exact location of the Frisian Front, which is situated in the broad zone around $54^{\circ} \mathrm{N}$ (Peeters and Peperzak, 1990). The Dogger Bank station (DB, $250 \mathrm{~km}$ off-shore) shows low nutrient availability throughout the year and due to its shallowness does not display stratification. The central North Sea (CNS, $450 \mathrm{~km}$ off-shore) shows the highest influence of 


\section{Compound synthesis under N/P limitation}

132 Atlantic Ocean water, which is low in nutrients and induces thermal stratification during summer.

133 The cruises took place 25 - 31 May 2011, 15 - 30 August 2011, 8 - 12 May 2012, 15 - 25 March

134 2013, and 24 April - 4 May 2013. The timing of the cruises coincided with pre-bloom conditions

135 (March 2013), the peak (April 2013) and the decline (Mid May 2012) of the spring-bloom as well

136 as post-bloom conditions (End May 2011) and the late summer period (August 2011).

137 Water for measurements and experiments was collected using a sampling rosette with 24 Niskin

138 bottles (12 L), equipped with a Sea-Bird SBE911+ CTD sampler (Sea-Bird Electronics Inc., USA)

139 to obtain water column distribution of salinity, temperature and photosynthetically available

140 radiation.

$141 \quad$ Nutrient addition experiments. The experimental design was according to Grosse et al. (2017).

142 In short, on-board nutrient addition experiments were performed to test for nutrient limitation.

143 Concurrently, treatments were enriched with ${ }^{13} \mathrm{C}$-DIC to trace photosynthetically fixed carbon into

144 individual biomolecules. Sub-surface water $(7 \mathrm{~m})$ was collected shortly before sunrise and directly

145 transferred into $10 \mathrm{~L}$ carboys. The following treatments were set up in duplicates: Control, $+\mathrm{N}$

146 (addition of $\left.80 \mu \mathrm{M} \mathrm{NaNO}_{3}\right),+\mathrm{P}\left(5 \mu \mathrm{M} \mathrm{K}_{2} \mathrm{HPO}_{4}\right)$ and $+\mathrm{NPSi}\left(80 \mu \mathrm{M} \mathrm{NaNO}_{3}, 5 \mu \mathrm{M} \mathrm{K} \mathrm{HPO}_{4}\right.$ and

$\left.14780 \mu \mathrm{M} \mathrm{Si}(\mathrm{OH})_{4}\right)$. All carboys were enriched with ${ }^{13} \mathrm{C}$-sodium bicarbonate $\left(99 \%{ }^{13} \mathrm{C}\right)$ to a final

148 labeling concentration of 1.5 to $2 \%$ of ambient DIC concentration (approximately $200 \mu \mathrm{M}$ ).

149 Carboys were incubated for $24 \mathrm{~h}$ in flow-through incubators on deck, which were continuously

150 flushed with seawater to assure in-situ temperature and light condition. Aliquot samples were

151 filtered over pre-combusted GF/F filters (Whatman, $4 \mathrm{~h}$ at $450^{\circ} \mathrm{C}$ ) for POC, AA and FA analysis. ,

152 The filtered volume ranged from $0.3-2.0 \mathrm{~L}$, depending on the phytoplankton density and POC

153 filters were pre-weight to enable partial filter analysis later. All filters were stored frozen at $-80^{\circ} \mathrm{C}$

154 until analysis. 


\section{Compound synthesis under N/P limitation}

155 During selected cruises, nutrient additions lasting $72 \mathrm{~h}$ were also carried out at the CZ and DB

156 to investigate if short-term changes in biomolecule synthesis differ from long-term changes and if

157 changes in biomolecule synthesis translate into shifts in relative biomolecule concentrations.

158 Therefore, a second set of nutrient treatments was set-up (control, +N, +P, +NPSi, in duplicates)

159 concurrently with the above mentioned incubations, the ${ }^{13} \mathrm{C}$-DIC was added after $48 \mathrm{~h}$ and the 160 incubations were terminated after $72 \mathrm{~h}$ as described above.

161 Analytical procedures. Biomolecule extraction protocols, analytical procedures and calculation

162 of ${ }^{13} \mathrm{C}$ uptake rates have been published in Grosse et al. $(2015,2017)$ and references therein. In

163 short, AA samples were acid hydrolyzed and after an ion-exchange clean-up step analyzed by LC-

164 IRMS using a Primsep A column, which separated a total of 17 individual AA (McCullagh et al.,

165 2006). Due to the analytical procedures glutamate and glutamine (Glx) co-elute and formed one

166 peak, as do aspartate and asparagine (Asx). All AA with the exception of tryptophan can be

167 measured with the method used, but because of very low concentrations of cysteine and

168 methionine both were excluded from the data analysis.

169 FA samples were extracted following the protocol of Bligh and Dyer (1959) and subsequently

170 separated into storage lipids, glycolipids and phospholipids by silicate column chromatography.

171 All three fractions were dried down and the glycolipid- and phospholipid fraction were combined

172 and are further referred to as structural lipids. After derivatization to fatty acid methyl esters

173 (FAMEs), FAME from both storage and structural lipids were separated by GC/C-IRMS using the

174 polar BPX-70 column. Fatty acids were notated $\mathrm{A}: \mathrm{B} \omega \mathrm{C}$, where $\mathrm{A}$ is the number of carbon

175 molecules in the fatty acid, B the number of double bonds and $\mathrm{C}$ the position of the first double

176 bond relative to the aliphatic end. In order to evaluate nutrient effects on the saturation of FA

177 composition, FA of the structural and storage pools were further divided by their degree of

178 saturation into saturated FA (SFA), mono-unsaturated FA (MUFA) and poly-unsaturated FA 
179 (PUFA). In order to reflect the contribution of different phytoplankton groups, PUFAs were

180 furthermore separated into PUFA containing 16 C-atoms (C16-PUFA; diatom specific) and PUFA

181 containing 18 C-atoms (C18-PUFA; flagellate specific; Dijkman and Kromkamp, 2006). The

182 PUFA 20:5 13 and 22:6 13 were evaluated individually because their ratio is indicative of the

183 dominating phytoplankton group. 20:5 $\omega 3 / 22: 6 \omega 3$ ratios $\geq 1$ signal the dominance of flagellates,

184 while a value < 1 is suggestive of a greater contribution of diatoms (Budge and Parrish, 1998).

185 Biosynthesis rates of each individual compound were calculated from ${ }^{13} \mathrm{C}$ incorporation rates

186 according to Grosse et al. (2015), and were added up in order to obtain values for each

187 biomolecule group (essential and non-essential AA and storage and structural FA. Throughout this

188 text, biomolecule concentrations and biosynthesis rates were reported relative to the total AA and

189 total FA, respectively. Unless noted differently, all data is shown as average ( \pm standard

190 deviation), $n=2$.

191 Statistical analysis. To explore differences in individual AA and FA composition under

192 different nutrient limitations, principle component analysis (PCA) was performed with the relative 193 contribution $(\%)$ of $(i)$ individual AA and 12 FA group concentrations to total AA and FA 194 concentrations (nmol C ( $\mu$ mol POC) $)^{-1}$ ) and (ii) individual AA and 12 FA group synthesis rates to 195 total AA and FA synthesis rates $\left(\right.$ nmol C $\left.(\mu \mathrm{mol} \mathrm{POC})^{-1} \mathrm{~d}^{-1}\right)$. The 12 FA groups comprise of 6

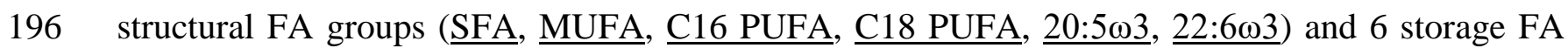

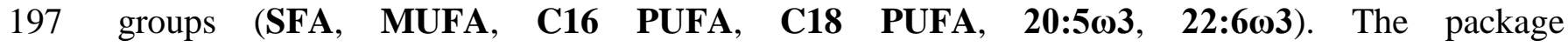
198 CRAN:factoMineR in the open source software R was used for the PCA analysis using a 199 correlation matrix (Lê et al., 2008, R Core Team, 2013). 


\section{Compound synthesis under N/P limitation}

Seasonal evolution of nutrients, resulting nutrient limitations and phytoplankton community composition have been discussed elsewhere (Burson et al., 2016; Grosse et al., 2017). In summary (Tab. 1), the development of inorganic nutrients showed a general decrease in concentrations over seasonal and special scales. The resulting DIN:DIP ratios suggested that near shore stations (CZ and $\mathrm{OG}$ ) were $\mathrm{P}$ limited during bloom-cruises and shifted towards $\mathrm{N}$ limitation thereafter, while stations farther offshore were limited by N-limited during all sampling periods (Burson et al., 2016; Grosse et al., 2017). However, Grosse et al. (2017) used the response in total AA biosynthesis in nutrient addition assays (after 24h) to identify the prevailing nutrient limitation (summarized in Tab. 2), which concur with nutrient limitations derived from DIN:DIP ratios (see above).

They also used the structural FA composition to determine the dominating phytoplankton community to be either dominated by diatoms or flagellates (summarized in Tab. 2). A few stations could not be assigned clearly as either diatom or flagellate dominated and are therefore referred to as "Mixed". The phytoplankton community composition showed the shift from diatom dominated communities to flagellate dominated communities that developed earlier in the year with increasing distance to the coast (Grosse et al., 2017).

\section{Individual amino acid contributions}

\section{Field conditions}

In un-amended incubations $(n=18)$, nutrient and community dependent differences in AA biosynthesis and composition were investigated using PCA (Fig. 3a, b). The PCA of AA biosynthesis showed that the first two principal components explained 54\% $(39 \%+15 \%)$ of variance in the dataset, while in PCA of AA concentration PC1 and PC2 explained 53\% (32\%+ $21 \%$ ) of the variance. For both biosynthesis and concentration a separation between not limited 


\section{Compound synthesis under N/P limitation}

227 mixed communities and N limited flagellate dominated communities occurred along the PC1 axis.

228 P (co-) limited stations did not cluster together but mixed with the other two groups. Concurrently,

229 there was a separation between essential AA (EAA) and non-essential AA (NEAA) in the

230 biosynthesis data along PC1 (Fig. 3a). EAA and Pro associated with non-limited communities,

231 while N-limited communities associated with all other NEAA. No such separation was observed

232 within the concentration data (Fig. 3b). There N limited communities were associated especially

233 with NEAA Asx, Glx and EAA Thr, while all other communities associate with EAAs as well as

234 NEAA Ala and Ser. A separation along the PC2 axis occurred as well and was associated with

235 Pro, Lys and Tyr. In order to demonstrate the variance between stations we plotted individual AA

236 concentration and biosynthesis of stations 4 and 18, representing a P limited diatom community

237 and a N limited flagellate community, respectively (Fig. 3c, d), clearly illustrating discussed

238 differences in AA contributions.

239 Across the whole dataset, there was substantial variation in both relative concentration and

240 biosynthesis when normalized to total AA (Fig. S1a). Variations were greater in biosynthesis than

241 in concentration, especially for NEAA such as Asx, Glx, Ala and Gly, while EAA Val, His and

242 Arg showed much smaller ranges in concentration and biosynthesis. Non-essential AA showed

243 higher relative biosynthesis compared to their concentration, while essential AA showed the

244 opposite trend, leading to a relative "over-synthesis" of non-essential AA and a relative "under-

245 synthesis" of essential AA in short-term (24 h) incubations.

246 Response to short-term nutrient addition

247 The effect of short-term nutrient addition (24 h) on AA biosynthesis was also studied using

248 PCA analysis (Fig. 4). Since AA biosynthesis seems to be nutrient specific we ran separate PCAs

249 for $(i) \mathrm{N}$-limited communities at 9 stations and (ii) not and P limited communities at the other 9

250 stations (as identified in Tab.2). The PCA of N limited communities explained 59\% (PC1: 44\%, 


\section{Compound synthesis under N/P limitation}

251 PC2: 15\%) of the variance in the data and a clear separation between treatments occurred (Fig. 4a).

252 Separation along the PC1 axis occurred between the NEAA Asx, Glx, Ala, and Gly, and all EAA

253 and Pro. The treatments where $\mathrm{N}$ limitation was relieved $(+\mathrm{N}$ and $+\mathrm{NPSi})$ associated with all EAA

254 and Pro, opposite to control and $+\mathrm{P}$ treatments, which continued to associated with NEAA thereby

255 demonstrating clear and swift shifts in synthesis rates. The $+\mathrm{P}$ treatments of four stations $(9,12$,

$25614,17)$ formed an exception and also developed an association with EAA, comparable to the $+\mathrm{N}$

257 and +NPSi, hereafter referred to as "Group X". Although these stations were primarily N limited

258 they showed co-limitation by $\mathrm{P}$ or $\mathrm{Si}$ and the addition of $\mathrm{P}$ also triggered a shift towards EAA at

259 these stations. In the PCA of not and P limited stations (Fig. 4b) PC1 and PC 2 explained 36\% and

$26021 \%$ of the variance, but differences in AA synthesis between different nutrient addition

261 treatments were not found.

\section{$262 \quad$ Fatty acid groups}

$263 \quad$ Field conditions

264 PCA was performed with FA group biosynthesis and concentration data (Fig. 5, $n=18$ ) and

265 revealed a separation between flagellate and diatom dominated communities with mixed

266 communities in between. The first two axes explained 55\% (PC1: 31\%, PC2: 24\%) and 62\% (PC1:

$26734 \%$, PC2: 28\%) of the variance in the biosynthesis and concentration data, respectively. As

268 expected, communities were associated with group specific FA (see Material \& Methods).

269 Flagellate communities were associated with structural and storage C18-PUFA as well as

270 structural 22:6ஸ3, while diatoms were associated with storage MUFA, storage and structural C16-

271 PUFA and storage 20:5 3 3. No clear effect of nutrient limitation could be observed. However, the

272 Si limited diatoms at station 7 clearly separated from other stations in the biosynthesis and showed

273 higher concentrations of structural MUFA. 


\section{Compound synthesis under N/P limitation}

274 Similar to individual amino acids, the contribution of the FA groups to total FA varied over

275 seasonal and spatial scales (Fig. S1b). Storage SFA and MUFA showed highest contributions as

276 well as highest variability in both concentration and biosynthesis. Compared to the relative

277 concentration, storage SFA and MUFA showed higher relative biosynthesis leading to a relative

278 "over-synthesis" of these compound groups, while structural FA groups showed the opposite trend

279 ("under-synthesis").

$280 \quad$ Response to nutrient addition

281 PCA was also performed on FA biosynthesis in nutrient addition treatments but revealed no 282 nutrient related short-term shifts ( $24 \mathrm{~h}$; data not shown), suggesting shifts in FA biosynthesis 283 occurred slower than shifts in AA. Therefore, we performed a PCA using the relative differences 284 in FA biosynthesis between control and nutrient addition treatments. Nutrient specific responses 285 were seen in both $\mathrm{N}$ and $\mathrm{P}$ limited station (9 stations and 4 stations, respectively, Fig.6). For $\mathrm{N}$ 286 limited stations the first two PC axes explained 64\% (PC1: 48\% + PC2: 16\%) of the variation. The $287+\mathrm{N}$ and + NPSi treatments responded with an increase in structural FA groups, while decreased $288 \mathrm{~N}: \mathrm{P}$ ratios in the $+\mathrm{P}$ treatment (induced through $\mathrm{PO}_{4}$ addition) caused synthesis of storage FA 289 groups to intensify. The $\mathrm{N}$ limited diatom community (Stn. 5) showed a shift towards storage C16 290 PUFA and storage 20:5 3 3 (Fig.6a).

291 For P limited stations the first two PC axes explained 66\% (PC1: 39\% + PC2: 27\%) of the 292 variation. P limited stations showed the same response to the relief of nutrient limitation; at the 293 majority of stations the $+\mathrm{P}$ and + NPSi treatments showed a relative increase in all structural FA 294 groups, while $+\mathrm{N}$ treatments (with increased N:P ratios during the incubation) increased synthesis 295 of storage SFA and storage C16 and C18 PUFA (Fig. 6b).

296 Longer-term effects of nutrient addition 


\section{Compound synthesis under N/P limitation}

Five longer-term incubations $(72 \mathrm{~h})$ were carried out to detect qualitative changes in AA synthesis and concentrations. Due to the low number of stations data evaluation using PCA was not possible and we decided to depict individual AA concentration and biosynthesis of the most severe $\mathrm{N}$ limited station (Stn. 13) because there the response to nutrient addition was expected to be greatest (Fig. 7a,b). Overall, nutrient additions showed similar effects in biosynthesis patterns as seen after $24 \mathrm{~h}$ for Stn.13. There was a persistent decrease of NEAA and increased EAA biosynthesis in the $+\mathrm{N}$ and + NPSi treatments, identical with the pattern found after $24 \mathrm{~h}$.

Responses at the P limited station (Stn.2) also occurred but only a few NEAAs decreased (e.g. Glx, Gly) and a few EAAs increased (e.g. Ile, Leu) in the + P and +NPSi treatments (Fig. S2a, b). A similar effect was not seen in Stn. 1 and 3 (data not shown). Furthermore, resulting relative changes in AA concentrations were difficult to identify at any station.

After $72 \mathrm{~h}$ shifts could be identified both in biosynthesis and concentration of relative FA distribution (Fig. 7c, d, S2c, d). The relief of N limitation $(+\mathrm{N}$ and $+\mathrm{NPSi}$, Stn. 13) and $\mathrm{P}$ limitation (+P and $+\mathrm{NPSi}, \mathrm{Stn} 2)$ caused a relative increase in the synthesis of structural MUFA and all three structural PUFA groups with a concurrent decrease in all storage FA groups. This shift in biosynthesis was also translated into the relative distribution of FA concentration, with increasing structural FA groups and decreasing storage FA groups. Consequently, quantitative and qualitative changes of FA concentrations need several days to become detectable.

\section{Discussion}

\section{Response of phytoplankton to nutrient limitation}

Coastal seas experience large perturbations in nutrient inputs, which may have important effects on the cellular composition of phytoplankton and its nutritional quality for higher trophic levels. Here we show that both, individual AA and groups of FA, exhibit specific responses to different 


\section{Compound synthesis under N/P limitation}

321 nutrient limitations in biosynthesis as well as composition. Biosynthesis patterns of individual AA

322 responded differently to $\mathrm{N}$ than to $\mathrm{P}$ limitation, and changes in relative AA contributions were

323 visible within $24 \mathrm{~h}$. Biosynthesis patterns in FA groups showed similar responses to $\mathrm{N}$ and $\mathrm{P}$

324 limitation and effects on relative FA group contribution were only clearly seen after $72 \mathrm{~h}$.

$325 \quad$ Amino acid dynamics

326 Although re-supplying the limiting nutrient led to an increase in total AA synthesis (Grosse et

327 al., 2017), only the $\mathrm{N}$ limited phytoplankton communities showed shifts in the distribution of

328 individual AA after $24 \mathrm{~h}$. Results from both un-amended and nutrient addition incubations showed

329 that under N limitation the pools of NEAA increased, especially Asx, Glx and Ala, while synthesis

330 of EAA and Pro decreased. The strong nutrient dependent separation of Glx and Asx from other

331 AA in PCAs of concentration, biosynthesis and nutrient additions (Fig. 3, 4) highlights their

332 function as pre-cursor in more complex pathways for essential AA (Fig. 1). The NEAA Pro stands

333 opposite to Glx even though it only requires a one-step reaction to synthesize Pro directly Glx.

334 However, Pro serves a special function in osmoregulation and in order to reduce $\mathrm{N}$ requirements

335 several phytoplankton groups are capable of substituting Pro with other osmolytes under N

336 limiting conditions (Bromke et al., 2013; Xiao et al., 2013). This causes Pro to be primarily

337 synthesized under $\mathrm{N}$ replete conditions and therefore to cluster with essential AA. The conversion

338 of NEAA to EAA relies on numerous additional enzymes, proteins themselves, and it may be

339 beneficial to reduce the production of these enzymes under $\mathrm{N}$ limitation. The up-regulation of AA

340 biosynthesis after $\mathrm{P}$ addition took much longer (several days) to be detected, compared to $\mathrm{N}$

341 limited stations (Grosse et al., 2017). It was suggested that rRNA and ribosome synthesis had to

342 precede the up-regulation of AA (protein) synthesis, as they are main P containing compounds in

343 phytoplankton and their content is reduced under P scarcity (Elser et al., 2000; Van Mooy and

344 Devol, 2008; Hessen et al., 2010). Furthermore, only a few selected AA changed their relative 
345 contribution to biosynthesis and no clear shift was visible that affects all AA (Fig. S2a, b), causing

346 a more uniform increase in the synthesis of individual AA. This would especially affect

347 translation, regulating the synthesis of protein chains, instead of being driven by the availability of

348 individual AA. Moreover, regulation at the gene-level is nutrient dependent as well. The lack and

349 the re-supply of $\mathrm{N}$ and $\mathrm{P}$ strongly affect gene expression patterns in a similar timely manner

350 (Morey et al., 2011; Yang et al., 2011). Genes related to ribosomes, carbohydrate metabolism, FA

351 metabolism as well as carbon fixation are both down- and up-regulated at different magnitudes

352 indicating changes in metabolic pathways and therefore highly affect protein composition hence

353 AA composition within cells (Morey et al., 2011; Yang et al., 2011; Bender et al., 2014). Silicon

354 starvation and replenishment in diatoms have similar effects on a large number of genes that

355 encode for many yet unknown proteins (Mock et al., 2008; Shrestha et al., 2012).

356 Interestingly, several N/P co-limited stations also showed the shifts towards EAA after P

357 addition (Group X, Fig. 4a). The response is similar to solely N limited stations and probably

358 depicts the response of different groups of phytoplankton within complex communities. Co-

359 incidentally, Burson et al. (2016) investigated phytoplankton group specific responses to nutrient

360 addition on one of these stations (Stn. 12). They found that dinoflagellates were not nutrient

361 limited, while nano-flagellates were limited by N, pico-eukaryotes were P limited, and Phaeocystis

362 sp., diatoms and pico-cyanobacteria showed N/P co-limitation. Co-limited phytoplankton may be

363 able to utilize remaining $\mathrm{N}$ concentrations after $\mathrm{P}$ addition (Harpole et al., 2011) causing AA

364 biosynthesis patterns to become similar to those after $\mathrm{N}$ addition.

$365 \quad$ Fatty acid dynamics

366 FA distribution is affected by multiple factors. Firstly, phytoplankton group specific FA shape 367 the FA composition of a community. On top of this, low nutrient availability regulates the degree 368 of FA saturation and the magnitude of storage FA synthesis. These responses seem to be the same 


\section{Compound synthesis under N/P limitation}

under $\mathrm{N}$ and $\mathrm{P}$ limited conditions. This shift from polar structural lipids (including phospholipids and glycolipids) towards neutral storage lipids, has been described earlier by other authors (Weers et al., 1997; Lynn et al., 2000; Mock and Kroon, 2002), however, only for changes in FA or lipid concentrations. Shift from PUFA to MUFA could also be attributed to changes in synthesis pathways, when desaturases and elongases cannot be synthesized in required amounts anymore under nutrient limiting conditions (Flynn et al., 1992). In our study all structural FA groups showed increased biosynthesis after $72 \mathrm{~h}$ but at different degrees after nutrient limitation was alleviated: PUFA groups increased synthesis up to sixfold, while increase of SFA and MUFA were about twofold or less (Fig. 7c,d). The delayed response in the FA fractions may be contributed to the fact that depending on present nutrient regimes FA can flow between storage and structural pools without requiring de-novo synthesis. Already synthesized storage FA may have been used to increase amounts of structural FA within $24 \mathrm{~h}$, but since they were not labeled by ${ }^{13} \mathrm{C}$ tracers this synthesis would have been undetected. This is supported by finding from Bender et al., (2014), who showed that genes involved in FA metabolism are also immediately regulated after changes in nutrient status.

To complete the list of parameters that affect biomolecule composition environmental parameters such as light availability and temperature must be mentioned briefly (Mortensen et al., 1988). With regards to FA, water temperatures impact membrane fluidity, causing phytoplankton to adapt by decreasing the degree of saturation in colder waters, e.g. decrease PUFA contributions (Tedesco and Duerr, 1989). This may have played a role in March when Mixed communities showed higher relative concentrations of structural MUFA and SFA.

Several groups of phytoplankton, including diatoms, have an additional way to cope with Pscarcity. They are able to substitute $\mathrm{P}$ containing membrane lipids for $\mathrm{N}$ or sulfur containing lipids thereby saving enough $\mathrm{P}$ to keep growth rates constant for several more cell divisions without 


\section{Compound synthesis under N/P limitation}

393 affecting FA composition (Van Mooy et al., 2009; Martin et al., 2011; Maat et al., 2016).This

394 mechanism may have played a role at the Coastal Zone station (Stn. 2-4), however, under the high

395 DIN:DIP ratios encountered (up to 333) in April this mechanisms may not have been effective to

396 overcome long-term P deficiencies and consequently also resulted in increased storage FA

397 concentrations and loss of PUFA during the peak of the spring bloom. This resulted in a lower

398 food quality of coastal phytoplankton groups as early as April during the peak of the spring bloom

399 (see below).

400 Biomolecule distribution in natural phytoplankton communities could be used to identify

401 prevailing nutrient limitations. Biosynthesis of individual AA in control incubations can be used to

402 distinguish between $\mathrm{N}$ limited and not/P limited stations as they cluster with NEAA and EAA

403 respectively (Fig. 3a). However, after nutrient addition long-term changes in AA concentrations

404 are only informative when considering total AA (Grosse et al., 2017), not individual AA (this

405 study). The main reason may be that AA concentrations were much higher than FA concentrations

406 (Grosse et al., 2017), hence changes in relative AA biosynthesis may take longer to translate into

407 relative AA concentrations. With average phytoplankton biomass turnover times of $\sim 7$ days

408 (Grosse et al., 2017) even the $72 \mathrm{~h}$ incubation period may have been too short to detect significant

409 shifts in AA composition. Therefore, future studies should incubate even longer to investigate this

410 issue further.

412 Contrary, nutrient-limitation was difficult to determine when only considering FA group

413 biosynthesis and concentration in control incubations (Fig. 5). This was due to the very diverse FA 414 composition between phytoplankton groups. Therefore, we suggest only considering the results of 415 the nutrient addition to identify nutrient specific effects, as species composition remained constant 


\section{Compound synthesis under N/P limitation}

416 during the 24-72 $\mathrm{h}$ incubations. In contrast to AA, changes in FA concentrations can be used to

417 determine the limiting nutrient in long-term nutrient addition assays. (this study).

\section{Consequences for food quality}

419 Biomolecule composition of phytoplankton has a direct effect on nutritional value for

420 consumers. Previous research has shown that EAA and PUFA are important determinants for 421 zooplankton growth (Müller-Navarra, 1995; Weers et al., 1997; Fink et al., 2011). In our study,

422 both pools were affected by nutrient limitations in diatom as well as photoautotrophic flagellate

423 communities, indicating that phytoplankton food quality varied substantially on both temporal and

424 spatial scales in the North Sea due to shifts in nutrient availability. It should be mentioned that

425 light intensity also modulates food quality, when increased light intensities result in higher relative

426 carbohydrate contribution, thus increasing $\mathrm{C}: \mathrm{N}$ and $\mathrm{C}: \mathrm{P}$ ratios and thereby decrease food quality

427 (van Oijen et al., 2007; Walter et al., 2015). However, light levels during incubations were chosen

428 in such a way that we exclude light stress to be a modulator of compound biosynthesis and

429 concentrations in our incubations.

430 Both diatoms and several autotrophic dinoflagellates are considered to have good food qualities

431 for grazers (Ianora et al., 1999; Turner et al., 2001; Turner et al., 2002). We found diatoms

432 dominating in early spring as well as throughout most of the year at the coastal zone (Grosse et al.,

433 2017), typically dominating spring bloom events in temperate zones (Smetacek, 1999;

434 McQuatters-Gollop et al., 2007). These communities were either not nutrient limited or

435 experienced P-limitation, which caused a decrease in AA quantity (Grosse et al., 2017) but did not

436 affect AA quality (this study, Fig. 4b). On the other hand, flagellates (including both

437 dinoflagellates and Phaeocystis sp., Burson et al., 2016; Grosse et al., 2017), which were dominant

438 at the three stations farther offshore showed strong $\mathrm{N}$ limitation in late spring and summer. The

439 decrease in AA quantity under N limitation (Grosse et al., 2017) was accompanied by a qualitative 


\section{Compound synthesis under N/P limitation}

440 shift towards NEAA (this study, Fig. 4a). Both low quality and quantity of AA negatively affect

441 consumer's growth (Guisande et al., 2000) and a lack of certain EAA was found to restrict the

442 reproduction of Daphnia and lead to changes in their life cycles (Fink et al., 2011; Koch et al.,

443 2011). Nutrient limitation affected FA synthesis in several ways. Relative FA synthesis was

444 shifted (i) away from structural FA towards storage FA and (ii) away from PUFA towards SFA,

445 especially under P limitation (Fig. 6b). Among the PUFA groups, the highly unsaturated FA

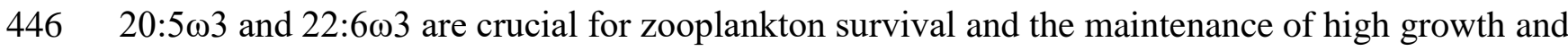

447 reproductive rates (Müller-Navarra, 1995; Burns et al., 2011). Consequently, trophic transfer

448 efficiency and food web structure will be affected too (Brett and Müller-Navarra, 1997).

449 Therefore, these tow FA are considered to be good indicators for food quality (Park et al., 2002).

450 In conclusion, food quality in terms of AA and FA are both negatively and concurrently affected

451 by nutrient limitation that will cause a decline in quantity and quality of individual essential

452 compounds.

453 Overall, the phytoplankton response to nutrient addition is rather general resulting with an

454 overall increase in AA synthesis before the increase of other structural compounds (Grosse et al.,

455 2017). However, the restricted pathways differ, i.e. $\mathrm{N}$ limitation inhibits protein synthesis and $\mathrm{P}$

456 limitation inhibits synthesis of RNA (Loladze and Elser, 2011; Alipanah et al., 2015). The release

457 of nutrient limitation may occur in proximity to river plumes, upwelling regions, or through input

458 of deep water upon mixing (breakdown of vertical stratification in the water column). Even though

459 these inputs may be brief, we show that the phytoplankton community responds within $24-72 \mathrm{~h}$.

460 Subsequent effects on zooplankton may also be observed on relative short time scales, especially

461 in micro-zooplankton population dynamics with short generation times (17 - 30 days, Halsband-

462 Lenk et al., 2002; Bonnet et al., 2005). Anthropogenically induced changes in nutrient inputs from

463 land push coastal seas more and more from N limited into P limited systems (Thingstad et al., 
464 1998; Philippart et al. 2000; Burson et al., 2016). Because zooplankton appears to be more

465 sensitive to $\mathrm{P}$ than to $\mathrm{N}$ limitation (Breteler et al., 2005), we recommend that future research also

466 considers other intracellular P-pools such as phospholipids, RNA and DNA. 
468

469

470

471

472

473

474

475

476

477

478

479

480

481

482

483

484

485

486

487

488

489

490

491

\section{References}

Alipanah, L., Rohloff, J., Winge, P., Bones, A.M., and Brembu, T. (2015). Whole-cell response to nitrogen deprivation in the diatom Phaeodactylum tricornutum. Journal of Experimental Botany. doi: 10.1093/jxb/erv340.

Arrigo, K.R. (2005). Marine microorganisms and global nutrient cycles. Nature 437, 349-355. doi: 10.1038/nature04159.

Arts, M., and Kohler, C. (2009). Ch. 9, in In Lipids in aquatic ecosystems 1st edn, ed. e.A.M.e. al.: Springer), 237-256.

Behrenfeld, M.J., Halsey, K.H., and Milligan, A.J. (2008). Evolved physiological responses of phytoplankton to their integrated growth environment. Philosophical Transactions of the Royal Society B-Biological Sciences 363(1504), 2687-2703. doi: 10.1098/rstb.2008.0019.

Bender, S.J., Durkin, C.A., Berthiaume, C.T., Morales, R.L., and Armbrust, E.V. (2014). Transcriptional responses of three model diatoms to nitrate limitation of growth. Frontiers in Marine Science. doi: 10.3389/fmars.2014.00003.

Bligh, E.G., and Dyer, W.J. (1959). A rapid method of total lipid extraction and purification. Canadian Journal of Biochemistry and Physiology 37(8), 911-917.

Blomqvist, S., Gunnars, A., and Elmgren, R. (2004). Why the limiting nutrient differs between temperate coastal seas and freshwater lakes: A matter of salt. Limnology and Oceanography 49(6), 2236-2241.

Bonnet, D., Richardson, A., Harris, R., Hirst, A., Beaugrand, G., Edwards, M., et al. (2005). An overview of Calanus helgolandicus ecology in European waters. Progress in Oceanography 65(1), 1-53. doi: 10.1016/j.pocean.2005.02.002.

Borsheim, K.Y., Vadstein, O., Myklestad, S.M., Reinertsen, H., Kirkvold, S., and Olsen, Y. (2005). Photosynthetic algal production, accumulation and release of phytoplankton storage 


\section{Compound synthesis under N/P limitation}

492

493

494

495

496

497

498

499

500

501

502

503

504

505

506

507

508

509

510

511

512

513

514

515

carbohydrates and bacterial production in a gradient in daily nutrient supply. Journal of Plankton Research 27(8), 743-755. doi: 10.1093/plankt/fbi047.

Breteler, W.C.M.K., Schogt, N., and Rampen, S. (2005). Effect of diatom nutrient limitation on copepod development: role of essential lipids. Marine Ecology Progress Series 291, 125-133.

Brett, M.T., and Müller-Navarra, D.C. (1997). The role of highly unsaturated fatty acids in aquatic food web processes. Freshwater Biology 38(3), 483-499. doi: 10.1046/j.13652427.1997.00220.x.

Bromke, M.A., Giavalisco, P., Willmitzer, L., and Hesse, H. (2013). Metabolic analysis of adaptation to short-term changes in culture conditions of the marine diatom Thalassiosira pseudonana. PLoS ONE 8(6), e67340. doi: 10.1371/journal.pone.0067340.

Budge, S.M., and Parrish, C.C. (1998). Lipid biogeochemistry of plankton, settling matter and sediments in Trinity Bay, Newfoundland. II. Fatty acids. Organic Geochemistry 29(5-7), 15471559.

Burns, C.W., Brett, M.T., and Schallenberg, M. (2011). A comparison of the trophic transfer of fatty acids in freshwater plankton by cladocerans and calanoid copepods. Freshwater Biology 56(5), 889-903. doi: 10.1111/j.1365-2427.2010.02534.x.

Burson, A., Stomp, M., Akil, L., Brussaard, C.P.D., and Huisman, J. (2016). Unbalanced reduction of nutrient loads has created an offshore gradient from phosphorus to nitrogen limitation in the North Sea. Limnology and Oceanography 61(3), 869 - 888. doi: 10.1002/lno.10257.

Claybrook, D.L. (1983). Nitrogen Metabolism, in Internal anatomy and physiological regulation. The biology of Crustacea, ed. L.H. Mantel. (New York: Academic Press, Inc), 163-213.

Dauwe, B., and Middelburg, J.J. (1998). Amino acids and hexosamines as indicators of organic matter degradation state in North Sea sediments. Limnology and Oceanography 43(5), 782798. doi: 10.4319/1o.1998.43.5.0782. 


\section{Compound synthesis under N/P limitation}

516 Dauwe, B., Middelburg, J.J., Herman, P.M.J., and Heip, C.H.R. (1999). Linking diagenetic

517 alteration of amino acids and bulk organic matter reactivity. Limnology and Oceanography

518 44(7), 1809-1814. doi: 10.4319/lo.1999.44.7.1809.

519 Diez, B., Van Nieuwerburgh, L., and Snoeijs, P. (2013). Water nutrient stoichiometry modifies the

520 nutritional quality of phytoplankton and somatic growth of crustacean mesozooplankton.

$521 \quad$ Marine Ecology Progress Series 489, 93-105. doi: 10.3354/meps10438.

522 Dijkman, N.A., Boschker, H.T.S., Middelburg, J.J., and Kromkamp, J.C. (2009). Group-specific

523 primary production based on stable-isotope labeling of phospholipid-derived fatty acids.

524 Limnology and Oceanography-Methods 7, 612-625. doi: 10.4319/lom.2009.7.612.

525 Dijkman, N.A., and Kromkamp, J.C. (2006). Phospholipid-derived fatty acids as chemotaxonomic

526 markers for phytoplankton: application for inferring phytoplankton composition. Marine

527 Ecology-Progress Series 324, 113-125. doi: 10.3354/meps324113.

528 Elser, J.J., Sterner, R.W., Gorokhova, E., Fagan, W.F., Markow, T.A., Cotner, J.B., et al. (2000).

529 Biological stoichiometry from genes to ecosystems. Ecology Letters 3(6), 540-550. doi:

$530 \quad$ 10.1111/j.1461-0248.2000.00185.x.

531 Falkowski, P.G. (2000). Rationalizing elemental ratios in unicellular algae. Journal of Phycology

$532 \quad 36(1), 3-6$.

533 Fidalgo, J.P., Cid, A., Torres, E., Sukenik, A., and Herrero, C. (1998). Effects of nitrogen source

534 and growth phase on proximate biochemical composition, lipid classes and fatty acid profile of

535 the marine microalga Isochrysis galbana. Aquaculture 166(1-2), 105-116.

536 Field, C.B., Behrenfeld, M.J., Randerson, J.T., and Falkowski, P. (1998). Primary production of

537 the biosphere: Integrating terrestrial and oceanic components. Science 281(5374), 237-240.

$538 \quad$ doi: $10.1126 /$ science.281.5374.237. 


\section{Compound synthesis under N/P limitation}

539 Fink, P., Pflitsch, C., and Marin, K. (2011). Dietary essential amino acids affect the reproduction

$540 \quad$ of the keystone herbivore Daphnia pulex. Plos One 6 (12). doi: 10.1371/journal.pone.0028498.

541 Flynn, K.J., Garrido, J.L., Zapata, M., Opik, H., and Hipkin, C.R. (1992). Changes in fatty acids,

542 amino acids and carbon/nitrogen biomass during nitrogen starvation of ammonium-grown and

543 nitrate-grown Isochrysis galbana. Journal of Applied Phycology 4(2), 95-104. doi:

$544 \quad 10.1007 / \mathrm{bf02442457.}$

545 Geider, R.J., and LaRoche, J. (2002). Redfield revisited: Variability of C:N:P in marine

546 microalgae and its biochemical basis. European Journal of Phycology 37(01), 1-17. doi:

547 doi:10.1017/S0967026201003456.

548 Grosse, J., van Breugel, P., and Boschker, H.T.S. (2015). Tracing carbon fixation in

549 phytoplankton-compound specific and total ${ }^{13} \mathrm{C}$ incorporation rates. Limnology and

$550 \quad$ Oceanography-Methods 13(6), 288-302. doi: 10.1002/lom3.10025.

551 Grosse, J., van Breugel, P., Brussaard, C.P.D., and Boschker, H.T.S. (2017). A biosynthesis view

552 on nutrient stress in coastal phytoplankton. Limnology and Oceanography 62(2), 490-506. doi:

$553 \quad 10.1002 /$ Ino.10439.

554 Guisande, C., Riveiro, I., and Maneiro, I. (2000). Comparisons among the amino acid composition

555 of females, eggs and food to determine the relative importance of food quantity and food

556 quality to copepod reproduction. Marine Ecology Progress Series 202, 135-142. doi:

$557 \quad 10.3354 / \operatorname{meps} 202135$.

558 Halsband-Lenk, C., Hirche, H.J., and Carlotti, F. (2002). Temperature impact on reproduction and

559 development of congener copepod populations. Journal of Experimental Marine Biology and

560 Ecology 271(2), 121-153. doi: 10.1016/s0022-0981(02)00025-4. 


\section{Compound synthesis under N/P limitation}

561 Harpole, W.S., Ngai, J.T., Cleland, E.E., Seabloom, E.W., Borer, E.T., Bracken, M.E.S., et al. (2011). Nutrient co-limitation of primary producer communities. Ecology Letters 14(9), 852862. doi: 10.1111/j.1461-0248.2011.01651.x.

Hessen, D.O., Jeyasingh, P.D., Neiman, M., and Weider, L.J. (2010). Genome streamlining and the elemental costs of growth. Trends in Ecology \& Evolution 25(2), 75-80. doi: 10.1016/j.tree.2009.08.004.

Howarth, R.W., and Marino, R. (2006). Nitrogen as the limiting nutrient for eutrophication in 568 coastal marine ecosystems: Evolving views over three decades. Limnology and Oceanography 51(1), 364-376. doi: 10.4319/lo.2006.51.1_part_2.0364.

Ianora, A., Miralto, A., Buttino, I., Romano, G., and Poulet, S.A. (1999). First evidence of some dinoflagellates reducing male copepod fertilization capacity. Limnology and Oceanography 44(1), 147-153. doi: 10.4319/lo.1999.44.1.0147.

Klausmeier, C.A., Litchman, E., Daufresne, T., and Levin, S.A. (2004). Optimal nitrogen-tophosphorus stoichiometry of phytoplankton. Nature 429(6988), 171-174. doi: 10.1038 /nature 02454.

Koch, U., Martin-Creuzburg, D., Grossart, H.-P., and Straile, D. (2011). Single dietary amino

Lê, S., Josse, J., and Husson, F. (2008). FactoMineR: An R Package for Multivariate Analysis.

581 Lin, H.Z., Tan, X.H., Zhou, C.P., Niu, J., Xia, D.M., Huang, Z., et al. (2015). Effect of dietary

582 arginine levels on the growth performance, feed utilization, non-specific immune response and 583 disease resistance of juvenile golden pompano Trachinotus ovatus. Aquaculture 437, 382-389. 


\section{Compound synthesis under N/P limitation}

584 Loladze, I., and Elser, J.J. (2011). The origins of the Redfield nitrogen-to-phosphorus ratio are in a

585 homoeostatic protein-to-rRNA ratio. Ecology Letters 14(3), 244-250. doi: 10.1111/j.1461-

$586 \quad$ 0248.2010.01577.x.

587 Ly, J., Philippart, C.J.M., and Kromkamp, J.C. (2014). Phosphorus limitation during a

588 phytoplankton spring bloom in the western Dutch Wadden Sea. Journal of Sea Research 88,

589 109-120. doi: 10.1016/j.seares.2013.12.010.

590 Lynn, S.G., Kilham, S.S., Kreeger, D.A., and Interlandi, S.J. (2000). Effect of nutrient availability

591 on the biochemical and elemental stoichiometry in the freshwater diatom Stephanodiscus

592 minutulus (Bacillariophyceae). Journal of Phycology 36(3), 510-522. doi: 10.1046/j.1529-

$593 \quad 8817.2000 .98251 . x$.

594 Maat, D.S., Bale, N.J., Hopmans, E.C., Sinninghe Damsté, J.S., Schouten, S., and Brussaard,

595 C.P.D. (2016). Increasing P limitation and viral infection impact lipid remodeling of the

596 picophytoplankter Micromonas pusilla. Biogeosciences 13(5), 1667-1676. doi: 10.5194/bg-13-

$597 \quad 1667-2016$.

598 Martin, P., Van Mooy, B.A.S., Heithoff, A., and Dyhrman, S.T. (2011). Phosphorus supply drives

599 rapid turnover of membrane phospholipids in the diatom Thalassiosira pseudonana. Isme

$600 \quad$ Journal 5(6), 1057-1060. doi: 10.1038/ismej.2010.192.

601 McCullagh, J.S.O., Juchelka, D., and Hedges, R.E.M. (2006). Analysis of amino acid ${ }^{13}$ C

602 abundance from human and faunal bone collagen using liquid chromatography/isotope ratio

603 mass spectrometry. Rapid Communications in Mass Spectrometry 20(18), 2761-2768. doi:

$604 \quad 10.1002 / \mathrm{rcm} .2651$.

605 McQuatters-Gollop, A., Raitsos, D.E., Edwards, M., and Attrill, M.J. (2007). Spatial patterns of 606 diatom and dinoflagellate seasonal cycles in the NE Atlantic Ocean. Marine Ecology Progress $607 \quad$ Series 339, 301-306. 


\section{Compound synthesis under N/P limitation}

608 Mock, T., and Kroon, B.M.A. (2002). Photosynthetic energy conversion under extreme conditions

609 - I: important role of lipids as structural modulators and energy sink under N-limited growth in 610 Antarctic sea ice diatoms. Phytochemistry 61(1), 41-51. doi: 10.1016/S0031-9422(02)00216-9.

611 Mock, T., Samanta, M.P., Iverson, V., Berthiaume, C., Robison, M., Holtermann, K., et al. (2008).

612 Whole-genome expression profiling of the marine diatom Thalassiosira pseudonana identifies

613 genes involved in silicon bioprocesses. Proceedings of the National Academy of Sciences

614 105(5), 1579-1584. doi: 10.1073/pnas.0707946105.

615 Morey, J.S., Monroe, E.A., Kinney, A.L., Beal, M., Johnson, J.G., Hitchcock, G.L., et al. (2011).

616 Transcriptomic response of the red tide dinoflagellate, Karenia brevis, to nitrogen and

617 phosphorus depletion and addition. BMC Genomics 12, 346-346. doi: 10.1186/1471-2164-12-

$618 \quad 346$.

619 Mortensen, S.H., Børsheim, K.Y., Rainuzzo, J., and Knutsen, G. (1988). Fatty acid and elemental

620 composition of the marine diatom Chaetoceros gracilis Schütt. Effects of silicate deprivation,

621 temperature and light intensity. Journal of Experimental Marine Biology and Ecology 122(2),

622 173-185. doi: http://dx.doi.org/10.1016/0022-0981(88)90183-9.

623 Müller-Navarra, D.C. (1995). Evidence that a highly unsatturated fatty acid limits Daphnia growth 624 in nature. Archiv Fur Hydrobiologie 132(3), 297-307.

625 OSPAR (1988). PARCOM recommendation 88/2: On the reduction in nutrients to the Paris 626 convention area. Publication number 88/2, Paris Commission.

627 OSPAR (2010). Quality Status Report 2010. OSPAR Commission. London. 176 pp.

628 Park, S., Brett, M.T., Müller-Navarra, D.C., and Goldman, C.R. (2002). Essential fatty acid 629 content and the phosphorus to carbon ratio in cultured algae as indicators of food quality for 630 Daphnia. Freshwater Biology 47(8), 1377-1390. doi: 10.1046/j.1365-2427.2002.00870.x. 


\section{Compound synthesis under N/P limitation}

631 Peeters, J.C.H., and Peperzak, L. (1990). Nutrient limitation in the North Sea - A bioassay

632 approach. Netherlands Journal of Sea Research 26(1), 61-73. doi: 10.1016/0077-

$633 \quad 7579(90) 90056-\mathrm{m}$.

634 Philippart, C.J.M., Cadee, G.C., van Raaphorst, W., and Riegman, R. (2000). Long-term

635 phytoplankton-nutrient interactions in a shallow coastal sea: Algal community structure,

636 nutrient budgets, and denitrification potential. Limnology and Oceanography 45(1), 131-144.

637 doi: $10.4319 / 10.2000 .45 .1 .0131$.

638 Piepho, M., Arts, M.T., and Wacker, A. (2012). Species-specific variations in fatty acid

639 concentrations of four phytoplankton species: Does phosphorus supply influence the effect of

$640 \quad$ light intensity or temperature? Journal of Phycology 48(1), 64-73. doi: 10.1111/j.1529-

$641 \quad$ 8817.2011.01103.x.

642 Plath, K., and Boersma, M. (2001). Mineral limitation of zooplankton: Stoichiometric constraints

643 and optimal foraging. Ecology 82(5), 1260-1269. doi: 10.1890/0012-

644 9658(2001)082[1260:mlozsc]2.0.co;2.

645 Quigg, A., Finkel, Z.V., Irwin, A.J., Rosenthal, Y., Ho, T.Y., Reinfelder, J.R., et al. (2003). The

646 evolutionary inheritance of elemental stoichiometry in marine phytoplankton. Nature

647 425(6955), 291-294. doi: 10.1038/nature01953.

648 R Core Team (2013). R: A language and environment for statistical computing. R Foundation for

649 Statistical Computing, Vienna, Austria. URL http://www.R-project.org/

650 Raubenheimer, D., Simpson, S.J., and Mayntz, D. (2009). Nutrition, ecology and nutritional

651 ecology: toward an integrated framework. Functional Ecology 23(1), 4-16.

652 Reitan, K.I., Rainuzzo, J.R., and Olsen, Y. (1994). Effect of nutrient limitation on fatty acid and

653 lipid content in marine microalgae. Journal of Phycology 30(6), 972-979. doi: 10.1111/j.0022-

$654 \quad$ 3646.1994.00972.x. 


\section{Compound synthesis under N/P limitation}

655 Renaud, S.M., Thinh, L.V., Lambrinidis, G., and Parry, D.L. (2002). Effect of temperature on

656 growth, chemical composition and fatty acid composition of tropical Australian microalgae

657 grown in batch cultures. Aquaculture 211(1-4), 195-214.

658 Shrestha, R.P., Tesson, B., Norden-Krichmar, T., Federowicz, S., Hildebrand, M., and Allen, A.E.

659 (2012). Whole transcriptome analysis of the silicon response of the diatom Thalassiosira

660 pseudonana. BMC Genomics 13(1), 1-16. doi: 10.1186/1471-2164-13-499.

661 Siron, R., Giusti, G., and Berland, B. (1989). Changes in the fatty acid composition of

$662 \quad$ Phaeodactylum tricornutum and Dunaliella tertiolecta during growth and under phosphorus

663 deficiency. Marine Ecology Progress Series 55(1), 95-100. doi: 10.3354/meps055095.

664 Smetacek, V. (1999). Diatoms and the Ocean Carbon Cycle. Protist 150(1), 25-32. doi:

665 https://doi.org/10.1016/S1434-4610(99)70006-4.

666 Smith, V.H., Tilman, G.D., and Nekola, J.C. (1999). Eutrophication: impacts of excess nutrient

667 inputs on freshwater, marine, and terrestrial ecosystems. Environmental Pollution 100(1-3),

$668 \quad 179-196$.

669 Sterner, R.W., and Elser, J.J. (2002). Ecological Stoichiometry: The Biology of Elements from

670 Molecules to the Biosphere. Princeton, NJ: Princeton University Press.

671 Sylvan, J.B., Quigg, A., Tozzi, S., and Ammerman, J.W. (2007). Eutrophication-induced

672 phosphorus limitation in the Mississippi River plume: Evidence from fast repetition rate

673 fluorometry. Limnology \& Oceanography 52(6), 2679-2685.

674 Tedesco, M.A., and Duerr, E.O. (1989). Light, temperature and nitrogen starvation effects on the

675 total lipid and fatty acid content and composition of Spirulina platensis UTEX 1928. Journal

676 of Applied Phycology 1(3), 201-209. doi: 10.1007/bf00003646. 


\section{Compound synthesis under N/P limitation}

677 Thingstad, T.F., Zweifel, U.L., and Rassoulzadegan, F. (1998). P limitation of heterotrophic

678 bacteria and phytoplankton in the northwest Mediterranean. Limnology and Oceanography 679 43(1), 88-94. doi: 10.4319/1o.1998.43.1.0088.

680 Troost, T.A., de Kluijver, A., and Los, F.J. (2014). Evaluation of eutrophication variables and 681 thresholds in the Dutch North Sea in a historical context — A model analysis. Journal of 682 Marine Systems 134, 45-56. doi: http://dx.doi.org/10.1016/j.jmarsys.2014.01.015.

683 Turner, J.T., Ianora, A., Esposito, F., Carotenuto, Y., and Miralto, A. (2002). Zooplankton feeding 684 ecology: does a diet of Phaeocystis support good copepod grazing, survival, egg production 685 and egg hatching success? Journal of Plankton Research 24(11), 1185-1195. doi: $686 \quad 10.1093 /$ plankt/24.11.1185.

687 Turner, J.T., Ianora, A., Miralto, A., Laabir, M., and Esposito, F. (2001). Decoupling of copepod 688 grazing rates, fecundity and egg-hatching success on mixed and alternating diatom and 689 dinoflagellate diets. Marine Ecology Progress Series 220, 187-199. doi: 10.3354/meps220187. 690 Van Mooy, B.A.S., and Devol, A.H. (2008). Assessing nutrient limitation of Prochlorococcus in 691 the North Pacific subtropical gyre by using an RNA capture method. Limnology \& 692 693 694 695 696 van Oijen, T., van Leeuwe, M.A., Gieskes W.W.C., and de Baar, \& H.J.W. (2007). Effects of iron 697 limitation on photosynthesis and carbohydrate metabolism in the Antarctic diatom 698 Chaetoceros brevis (Bacillariophyceae). European Journal of Phycology 39(2), 161-171, doi: 


\section{Compound synthesis under N/P limitation}

700 Vrede, T., Dobberfuhl, D.R., Kooijman, S., and Elser, J.J. (2004). Fundamental connections

701 among organism $\mathrm{C}: \mathrm{N}:$ P stoichiometry, macromolecular composition, and growth. Ecology

702 85(5), 1217-1229. doi: 10.1890/02-0249.

703 Walter, B., Peters, J., van Beusekom, J.E.E., St. John, M.A. (2015). Interactive effects of

704 temperature and light during deep convection: a case study on growth and condition of the

705 diatom Thalassiosira weissflogii. ICES Journal of Marine Science 72(6), 2061-2071. doi:

$706 \quad$ 10.1093/icesjms/fsu218

707 Weers, P.M.M., Siewertsen, K., and Gulati, R.D. (1997). Is the fatty acid composition of Daphnia

708 galeata determined by the fatty acid composition of the ingested diet? Freshwater Biology

709 38(3), 731-738. doi: 10.1046/j.1365-2427.1997.00238.x.

710 Xiao, Y., Zhang, J., Cui, J., Feng, Y., and Cui, Q. (2013). Metabolic profiles of Nannochloropsis

711 oceanica IMET1 under nitrogen-deficiency stress. Bioresource Technology 130(0), 731-738.

712 doi: http://dx.doi.org/10.1016/j.biortech.2012.11.116.

713 Xin, L., Hong-ying, H., Ke, G., and Ying-xue, S. (2010). Effects of different nitrogen and

714 phosphorus concentrations on the growth, nutrient uptake, and lipid accumulation of a

715 freshwater microalga Scenedesmus sp. Bioresource Technology 101(14), 5494-5500. doi:

$716 \quad$ http://dx.doi.org/10.1016/j.biortech.2010.02.016.

717 Xu, J., Yin, K., He, L., Yuan, X., Ho, A.Y.T., and Harrison, P.J. (2008). Phosphorus limitation in

718 the northern South China Sea during late summer: Influence of the Pearl River. Deep-Sea

$719 \quad$ Research I 55, 1330-1342. doi: doi:10.1016/j.dsr.2008.05.007.

720 Yang, I., Beszteri, S., Tillmann, U., Cembella, A., and John, U. (2011). Growth-and nutrient-

721 dependent gene expression in the toxigenic marine dinoflagellate Alexandrium minutum.

722 Harmful Algae 12, 55-69.

723 


\section{Acknowledgments}

725 The authors thank the captain and crew of the R/V Pelagia for their help and support during the

726 cruises, and Amanda Burson, Ruben van Drie and Elodie Burrillon for their skilled assistance with

727 experimental work onboard. Special thanks to the Nutrient Lab at NIOZ-Texel for providing

728 nutrient data, the Analytical Lab at NIOZ-Yerseke for the analysis of pigment samples and the

729 reviewers for their constructive comments. This research is part of the CHARLET project and was

730 supported by the Netherlands Organization for Scientific Research (NWO) to HTSB (grant ZKO

$731839.10 .511)$. 


\section{$732 \quad$ Figure legends}

733 Fig. 1: Schematic diagram of AA synthesis in phytoplankton. Amino acids essential for higher

734 trophic levels were underlined. 3-PGA = 3 phosphoglyceric acid, Ser $=$ serine, Gly = glycine, Cys

$735=$ cysteine, $\mathrm{PEP}=$ phosphoenolpyruvate, Try $=$ tryptophane, Tyr $=$ tyrosine, Phe $=$ phenylalanine,

736 Ala $=$ alanine, Leu $=$ leucine, $\mathrm{Val}=$ valine, $\mathrm{TCA}=$ tricarboxylic acid cycle, Asx $=$ combined pools

737 of aspartate/asparagine, $\mathrm{Met}=$ methinone, $\mathrm{Thr}=$ threonine, Ile $=$ isoleucine, Lys $=$ lysine, $\mathrm{Glx}=$

738 combined pools of glutamate/glutamine, $\mathrm{His}=$ histidine, Pro = proline, Arg = arginine. Met, Cys

739 and Try were not detected in this study.

740

741 Fig. 2: Map of stations revisited during five cruises between 2011-2013

742

743 Fig. 3: PCA biplot of relative contribution of individual AA to total AA biosynthesis (a) and

744 concentration (b). Symbol shape refers to the dominating phytoplankton community and symbol

745 color indicates limiting nutrients. Panel $\mathrm{c}$ and d give examples for range of AA contributions for

746 the stations CZ/End May (station 4, P limited, diatom dominated) and CNS/August (station 18, N

747 limited, flagellate dominated). Shown are averages $\pm \mathrm{SD}, n=2$. Essential AA were underlined.

749 Fig. 4: PCA biplot show biosynthesis of individual AA in nutrient addition treatments after $24 \mathrm{~h}$.

750 Phytoplankton was separated into N-limited flagellate and mixed communities (a; 9 stations,

$751 n=36)$ and not/P limited communities (b; 9 stations, $n=36)$. Ellipses encircle distribution of the

752 same treatment and Group X (black), respectively. Essential AA were underlined.

754 Fig. 5: PCA biplot of relative contribution of FA groups to total FA biosynthesis (a) and C

755 concentration (b). Symbol shape refers to the dominating group of the phytoplankton community 
756 and symbol color indicates prevailing nutrient limitation. FA groups are separated into structural

757 FA ( $\underline{\text { underlined }}$ ) and storage FA (bold) groups. SFA = saturated FA, MUFA = mono-unsaturated

758 FA, C16-PUFA/ C18-PUFA = poly-unsaturated FA containing 16 and $18 \mathrm{C}$ atoms, respectively.

759

760 Fig. 6: PCA biplot show shifts in biosynthesis of FA groups in nutrient addition treatments

761 relative to the Control treatment after $24 \mathrm{~h}$. Phytoplankton was separated into $\mathrm{N}$ limited

762 communities (a; 9 stations, $n=27$ ) and P limited (b; 4 stations, $n=12)$. Structural FA groups are

763 underlined, storage FA groups are shown in bold.

764

765 Fig. 7: Distribution of individual AA and FA groups in concentrations (open bars) and

766 biosynthesis (striped bars) after 72h at the Dogger Bank in Mid May (N limited, mixed

767 community).

768 


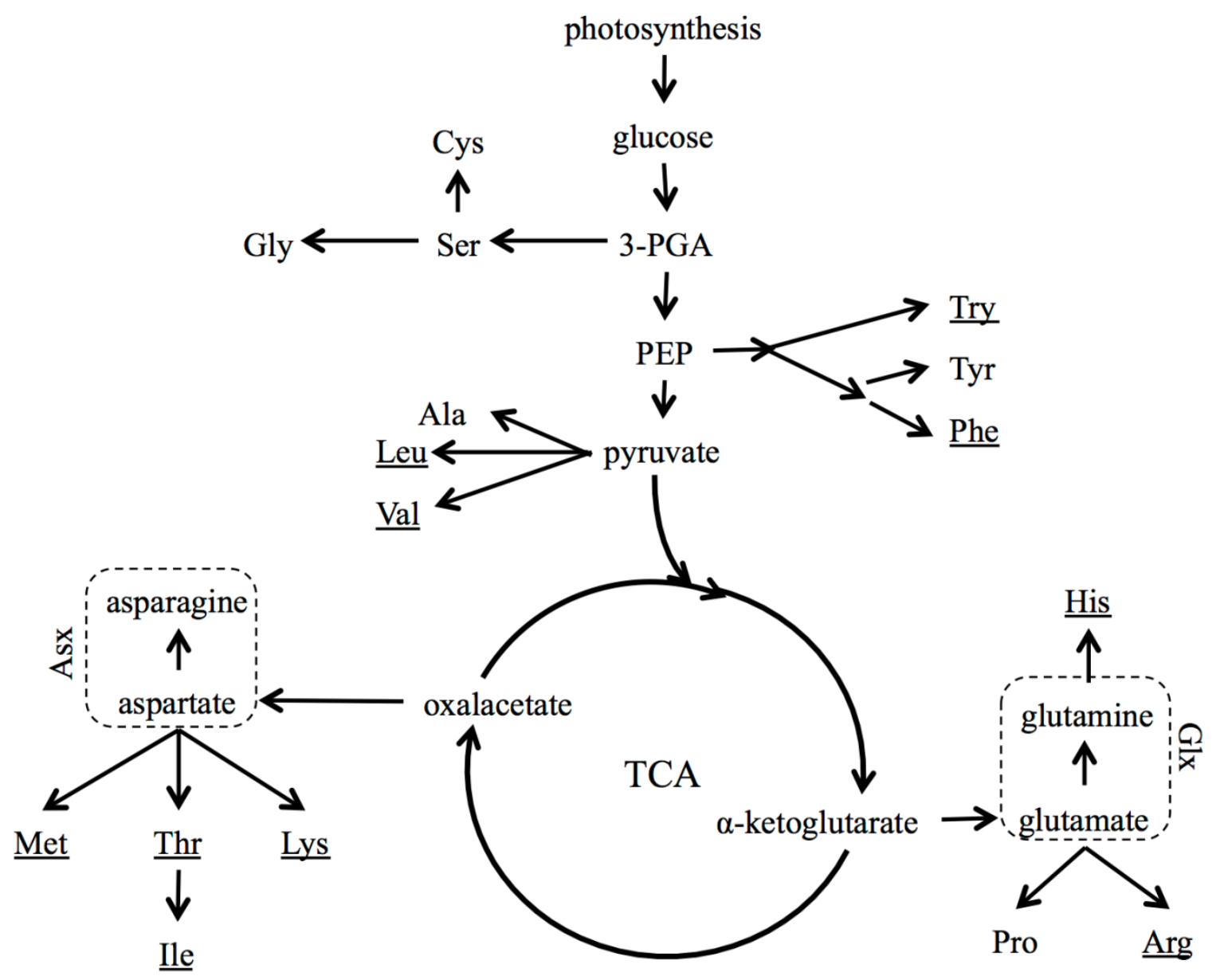

769

$770 \quad$ Fig. 1

771 


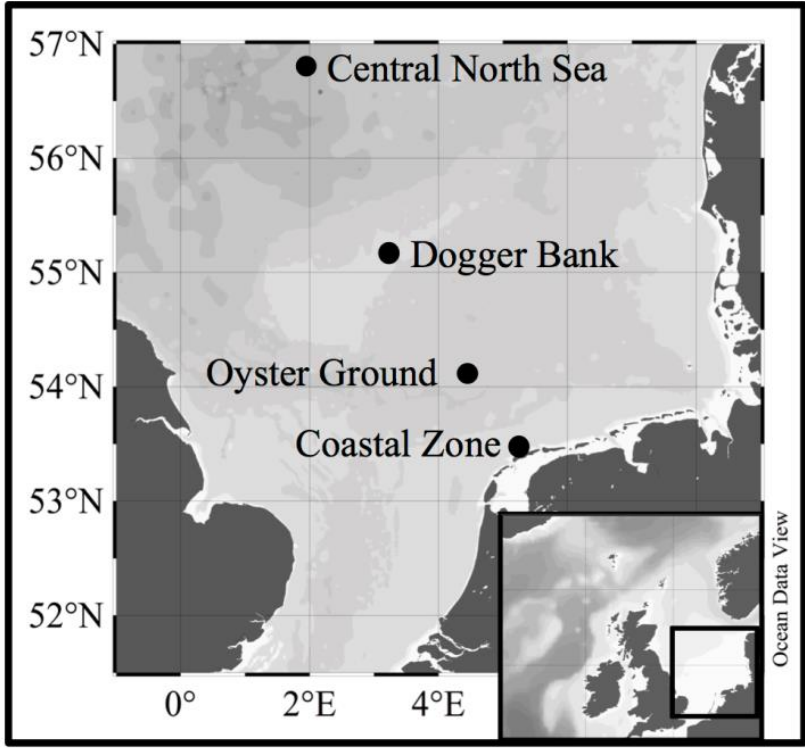

$773 \quad$ Fig.2 

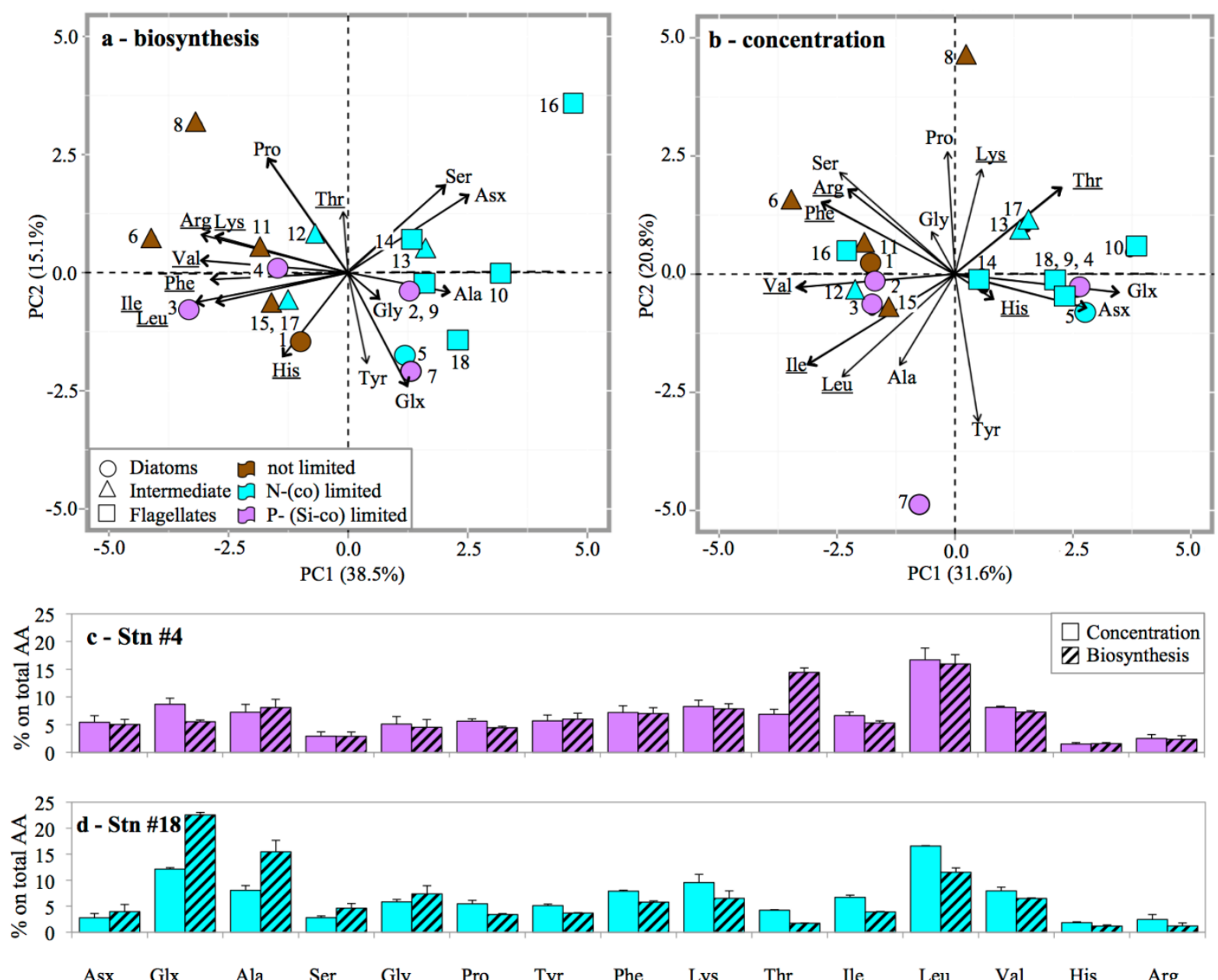

\section{$776 \quad$ Fig.3}



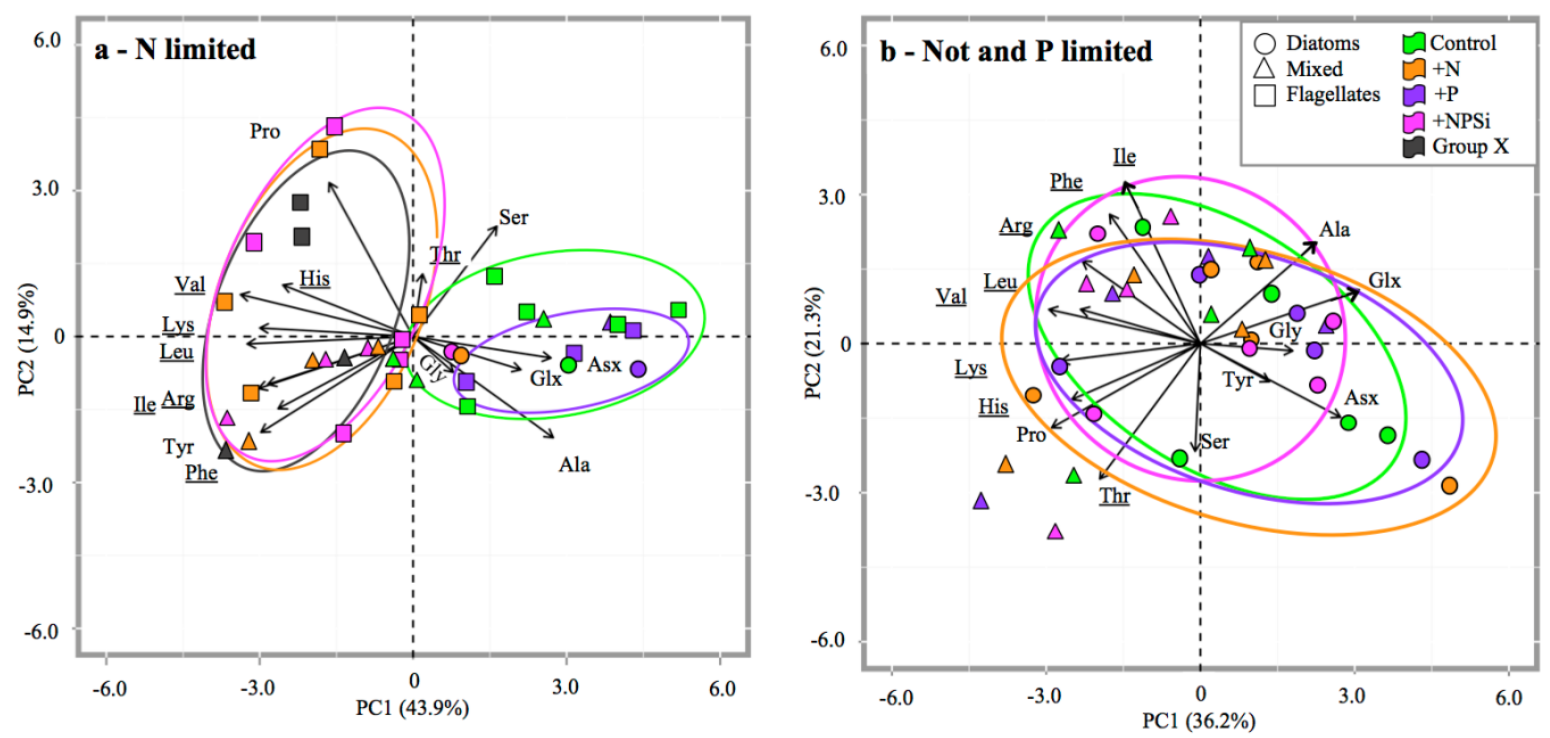

778

$779 \quad$ Fig.4 

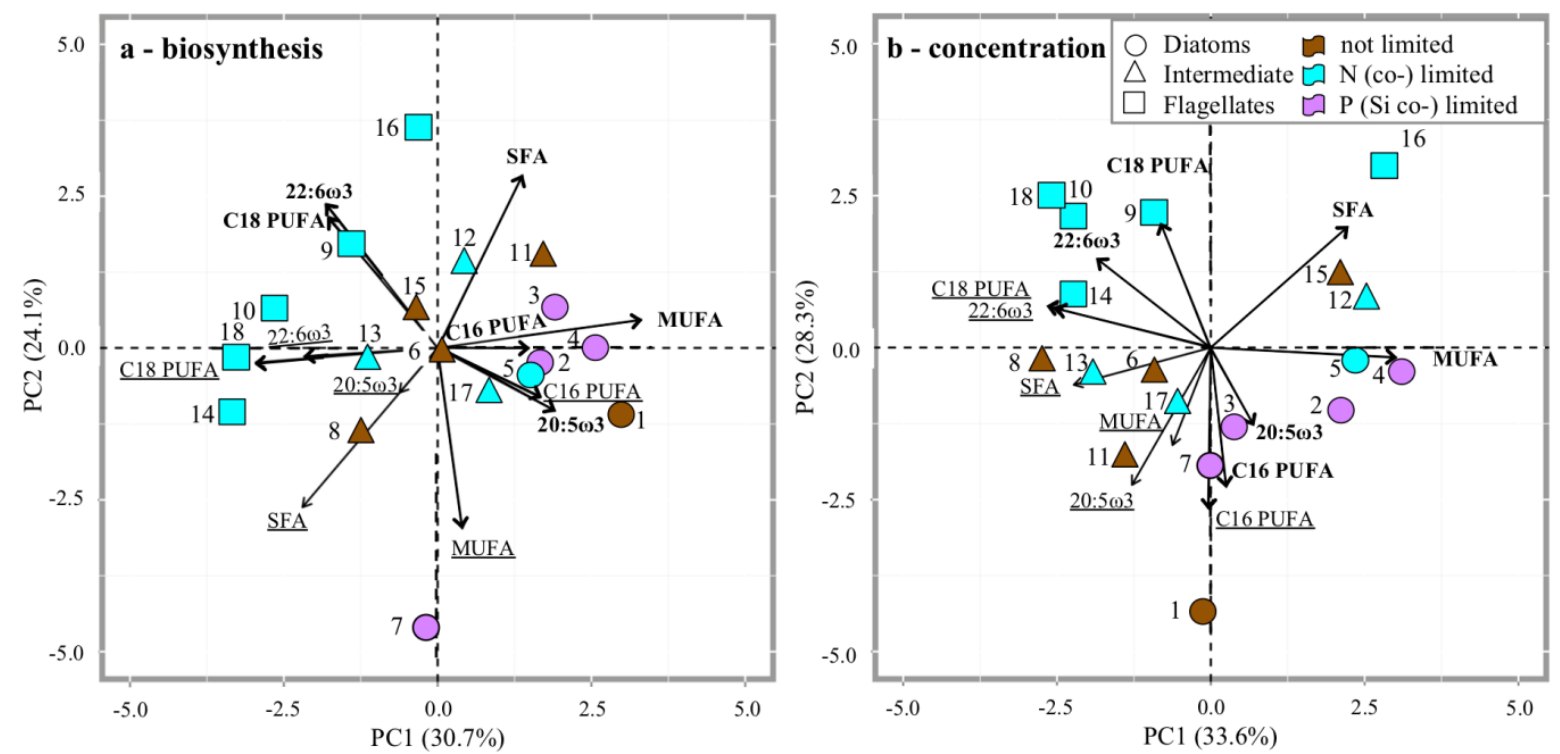

$781 \quad$ Fig. 5 

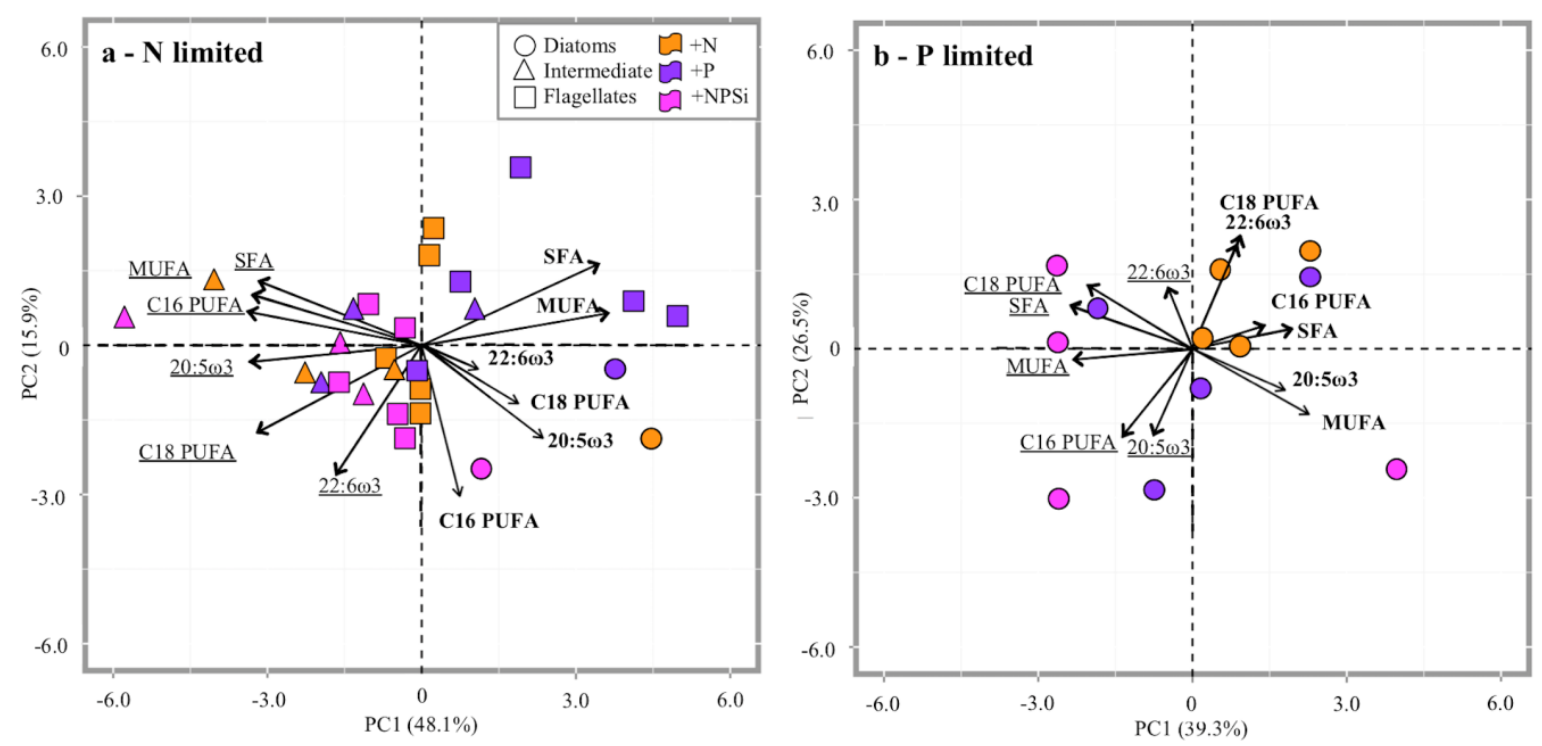

783 Fig. 6

784 

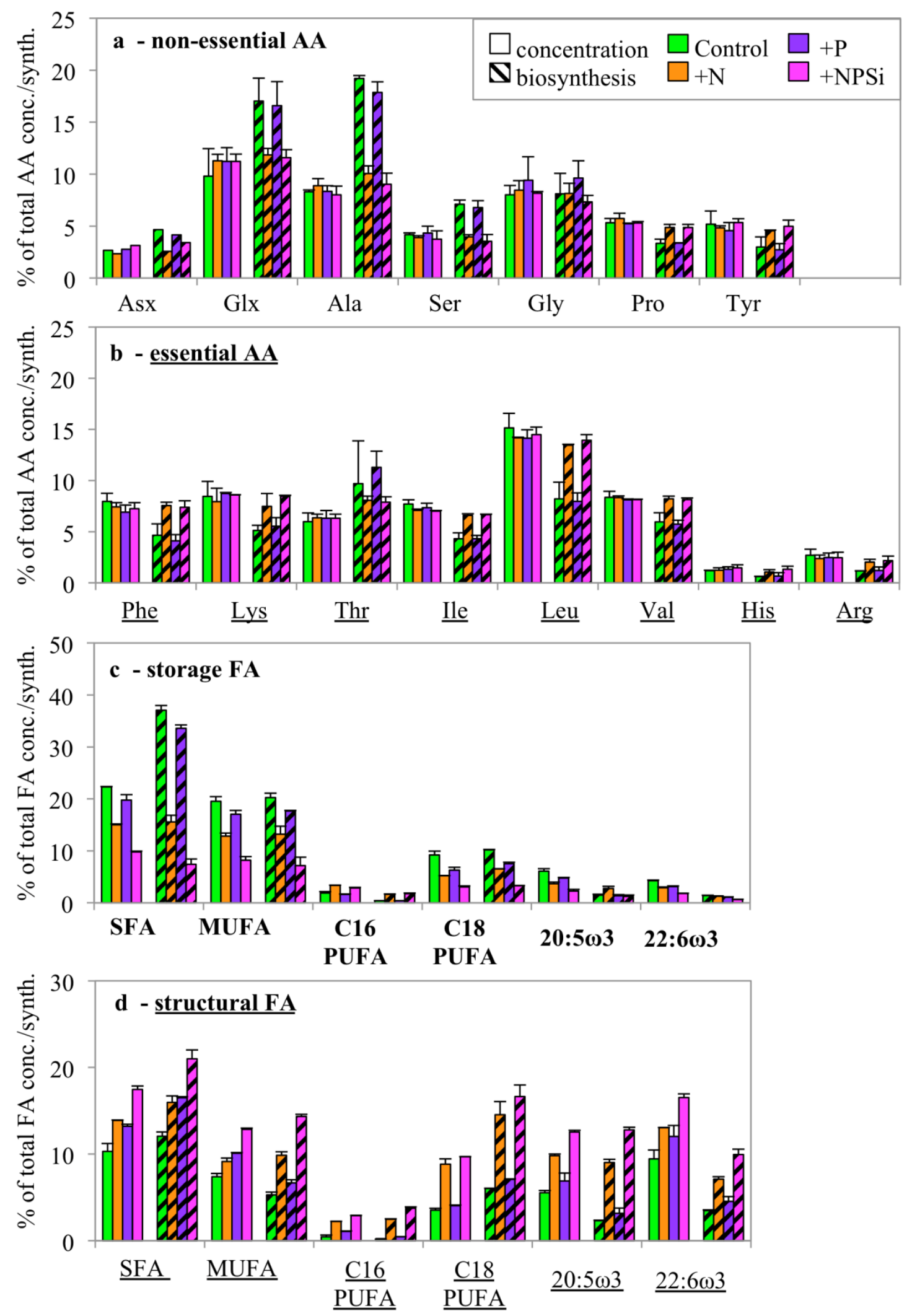

Fig. 7 
789 Table 1: Overview of nutrient concentrations and resulting DIN:DIP ratios at each station as

790 determined in Grosse et al. (2017). Station \# can be used to identify stations in PCA plots. DIN =

791 nitrate + nitrite + ammonia. $<\mathrm{DL}=$ below detection limit, for $\mathrm{Si}(\mathrm{OH})_{4}$ limit is $0.03 \mu \mathrm{M}$.

792

\begin{tabular}{|c|c|c|c|c|}
\hline Month (Stn. \#) & $\begin{array}{c}\mathrm{DIN} \\
{[\mu \mathrm{M}]}\end{array}$ & $\begin{array}{c}\mathrm{PO}_{4} \\
{[\mu \mathrm{M}]}\end{array}$ & $\begin{array}{c}\mathrm{Si}(\mathrm{OH})_{4} \\
{[\mu \mathrm{M}]}\end{array}$ & DIN:DIP \\
\hline \multicolumn{5}{|c|}{ Coastal Zone $\left(\mathrm{CZ} ; 5.150^{\circ} \mathrm{E} / 53.401^{\circ} \mathrm{N}\right)$} \\
\hline March (1) & 38.5 & 0.71 & 16.6 & 54 \\
\hline April (2) & 16.3 & 0.05 & 0.13 & 325 \\
\hline Mid May (3) & 9.56 & 0.05 & 0.37 & 191 \\
\hline End May (4) & 5.64 & 0.09 & 1.1 & 63 \\
\hline August (5) & 0.39 & 0.02 & 0.37 & 20 \\
\hline \multicolumn{5}{|c|}{ Oyster Ground $\left(\mathrm{OG} ; 4.330^{\circ} \mathrm{E} / 54.130^{\circ} \mathrm{N}\right)$} \\
\hline March (6) & 9.90 & 0.54 & 6.3 & 18 \\
\hline April (7) & 1.09 & 0.04 & $<\mathrm{DL}$ & 27 \\
\hline Mid May (8) & 1.28 & 0.16 & 1.4 & 8 \\
\hline End May (9) & 0.48 & 0.03 & 0.77 & 16 \\
\hline August (10) & 0.12 & 0.13 & 2.2 & 1 \\
\hline \multicolumn{5}{|c|}{ Dogger Bank $\left(\mathrm{DB} ; 3.150^{\circ} \mathrm{E} / 55.170^{\circ} \mathrm{N}\right)$} \\
\hline March (11) & 5.32 & 0.54 & 4.7 & 10 \\
\hline April (12) & 0.27 & 0.14 & 0.03 & 2 \\
\hline Mid May (13) & 0.21 & 0.06 & 0.09 & 4 \\
\hline End May (14) & 0.10 & 0.09 & 0.44 & 1 \\
\hline \multicolumn{5}{|c|}{ Central North Sea $\left(\mathrm{CNS} ; 2.165^{\circ} \mathrm{E} / 56.579^{\circ} \mathrm{N}\right)$} \\
\hline March (15) & 6.51 & 0.53 & 2.5 & 12 \\
\hline April (16) & 0.24 & 0.16 & 0.28 & 2 \\
\hline Mid May (17) & 1.28 & 0.17 & 0.84 & 8 \\
\hline August (18) & 0.10 & 0.02 & 0.76 & 5 \\
\hline
\end{tabular}

793

794 
795 Table 2: The table summarizes treatments that responded to nutrient addition by increasing

796 relative biosynthesis of amino acids as shown in Grosse et al. 2017. Listed first is the treatment

797 with the highest increase in AA biosynthesis (compared to un-amended control), followed by

798 treatments with equal increase $(=)$ of lower increase $(>)$. Additionally, listed are the derived

799 nutrient limitations prevailing at each station and the phytoplankton community structure which

800 has been determined in Grosse et al. (2017) using individual structural FA.

801 Data included in different PCA datasets:

802 *Included in Fig. 4a, Control, +N, +P, +NPSi treatment

803 Included in Fig. 4b, Control, +N, +P, +NPSi treatment

804 Included in Fig. 6a; differences Control to +N, Control to +P, Control to +NPSi treatment

805 Included in Fig. 6b; differences Control to $+\mathrm{N}$, Control to $+\mathrm{P}$, Control to + NPSi treatment 806

\begin{tabular}{|c|c|c|c|}
\hline Month (Stn. \#) & $\begin{array}{l}\text { Increase in relative } \\
\text { AA biosynthesis }\end{array}$ & $\begin{array}{l}\text { Inferred nutrient } \\
\text { limitation }\end{array}$ & $\begin{array}{r}\text { Phytoplankton } \\
\text { community }\end{array}$ \\
\hline \multicolumn{4}{|l|}{ Coastal Zone (CZ) } \\
\hline $\operatorname{March}(1)^{\dagger}$ & --- & --- & Diatom \\
\hline April (2) ${ }^{\dagger}$ & $+\mathrm{NPSi}>+\mathrm{P}($ after $72 \mathrm{~h})$ & $\mathrm{P} / \mathrm{Si}$ & Diatom \\
\hline 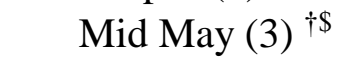 & $+\mathrm{NPSi}>+\mathrm{P}($ after $72 \mathrm{~h})$ & $\mathrm{P} / \mathrm{Si}$ & Diatom \\
\hline End May (4) $\uparrow \$$ & $+\mathrm{NPSi}>+\mathrm{P}$ & $\mathrm{P} / \mathrm{Si}$ & Diatom \\
\hline August (5) ** & $+\mathrm{N}=+\mathrm{NPSi}$ & $\mathrm{N}$ & Diatom \\
\hline \multicolumn{4}{|l|}{ Oyster Ground (OG) } \\
\hline $\operatorname{March}(6)^{\dagger}$ & --- & --- & Mixed \\
\hline April (7) $\uparrow \$$ & $+\mathrm{NPSi}>+\mathrm{N}=+\mathrm{P}$ & $\mathrm{Si} / \mathrm{N} / \mathrm{P}$ & Diatom \\
\hline $\operatorname{Mid} \operatorname{May}(8)^{\dagger}$ & --- & --- & Mixed \\
\hline End May (9) ${ }^{*}+$ & $\mathrm{NPSi}>+\mathrm{N}$ & $\mathrm{N} / \mathrm{Si}$ & Flagellate \\
\hline August (10) $)^{* \vdots}$ & $+\mathrm{N}=+\mathrm{NPSi}$ & $\mathrm{N}$ & Flagellate \\
\hline \multicolumn{4}{|l|}{ Dogger Bank (DB) } \\
\hline $\operatorname{March}(11)^{\dagger}$ & --- & --- & Mixed \\
\hline April (12) ${ }^{* \dagger}$ & $+\mathrm{NPSi}>+\mathrm{N}$ & $\mathrm{N} / \mathrm{Si}$ & Mixed \\
\hline Mid May $(13)^{* *}$ & $+\mathrm{N}=+\mathrm{NPSi}$ & $\mathrm{N}$ & Flagellate \\
\hline End May (14) ${ }^{*}$ & $+\mathrm{N}=+\mathrm{NPSi}$ & $\mathrm{N}$ & Flagellate \\
\hline \multicolumn{4}{|c|}{ Central North Sea (CNS) } \\
\hline $\operatorname{March}(15)^{\dagger}$ & --- & --- & Mixed \\
\hline April (16) ${ }^{* \dagger}$ & $+\mathrm{N}=+\mathrm{NPSi}$ & $\mathrm{N}$ & Flagellate \\
\hline Mid May (17) ${ }^{*}$ & $+\mathrm{N}=+\mathrm{NPSi}>+\mathrm{P}$ & $\mathrm{N} / \mathrm{P}$ & Mixed \\
\hline August (18) & $+\mathrm{N}=+\mathrm{NPSi}$ & $\mathrm{N} / \mathrm{Si}$ & Flagellate \\
\hline
\end{tabular}

807

808 


\section{Supplemental Information}

2 Nutrient limitation driven dynamics of amino acids and fatty acids in coastal phytoplankton

3 Julia Grosse, Corina P.D. Brussaard and Henricus T. S. Boschker

4 

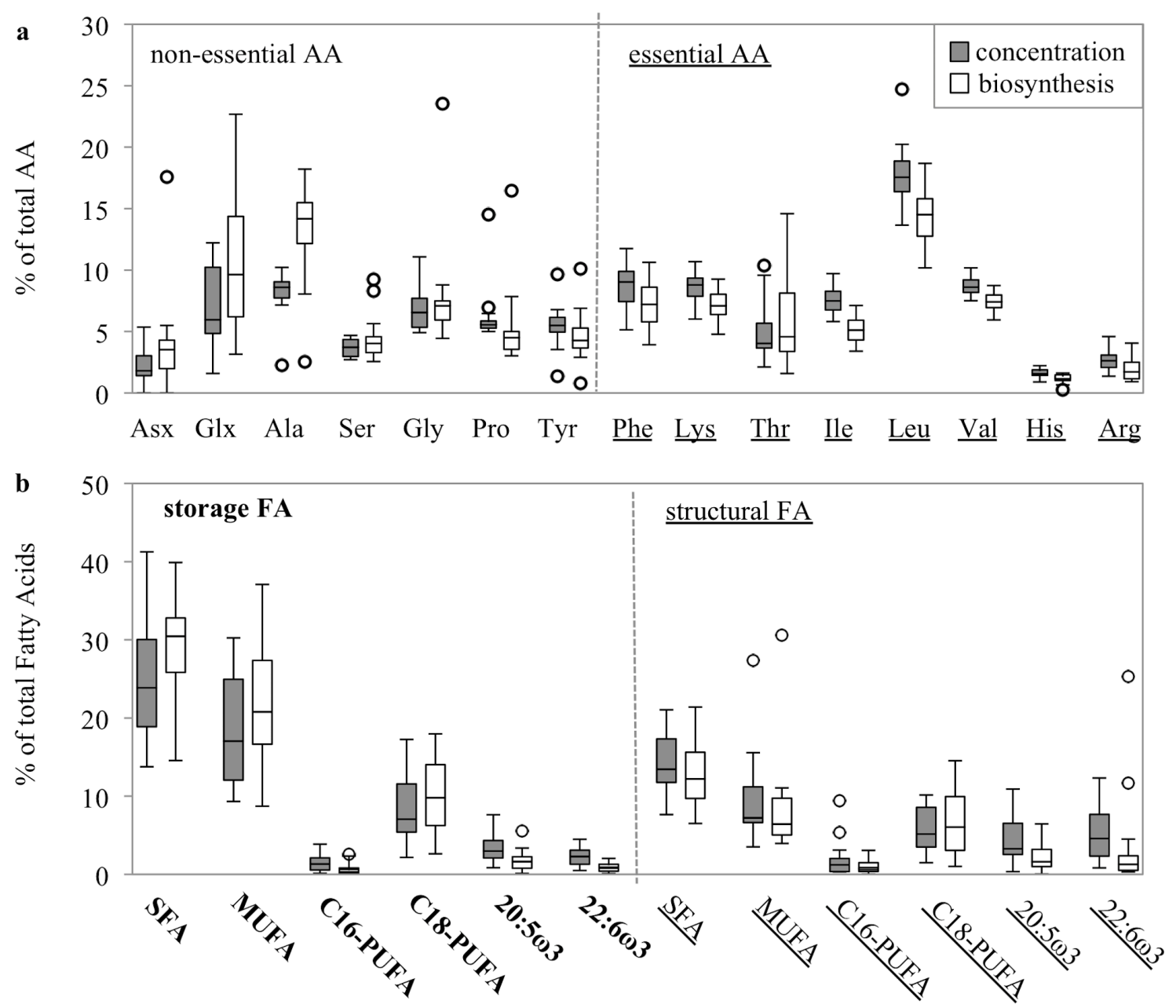

6 Fig. S1: Box-plot showing the contribution of individual amino acids to total amino acids in C (a)

7 contribution of fatty acid groups to total fatty acids in C (b). Grey bars represent concentration data and

8 white bars the biosynthesis data for un-amended incubations (Control) from all cruises and stations $(n=$

936 , including duplicates). Horizontal lines are medians, boxes show the interquartile range (IQR), error

10 bars show the full range excluding outliers (circles) defined as being more than \pm 1.5 IQR outside the

11 box. Essential AA and structural FA were underlined, storage FA are shown in bold. SFA = saturated

12 FA, MUFA = mono-unsaturated FA, C16-PUFA/ C18-PUFA = poly-unsaturated FA containing 16 and

$1318 \mathrm{C}$ atoms, respectively. Circles represent outliers. 

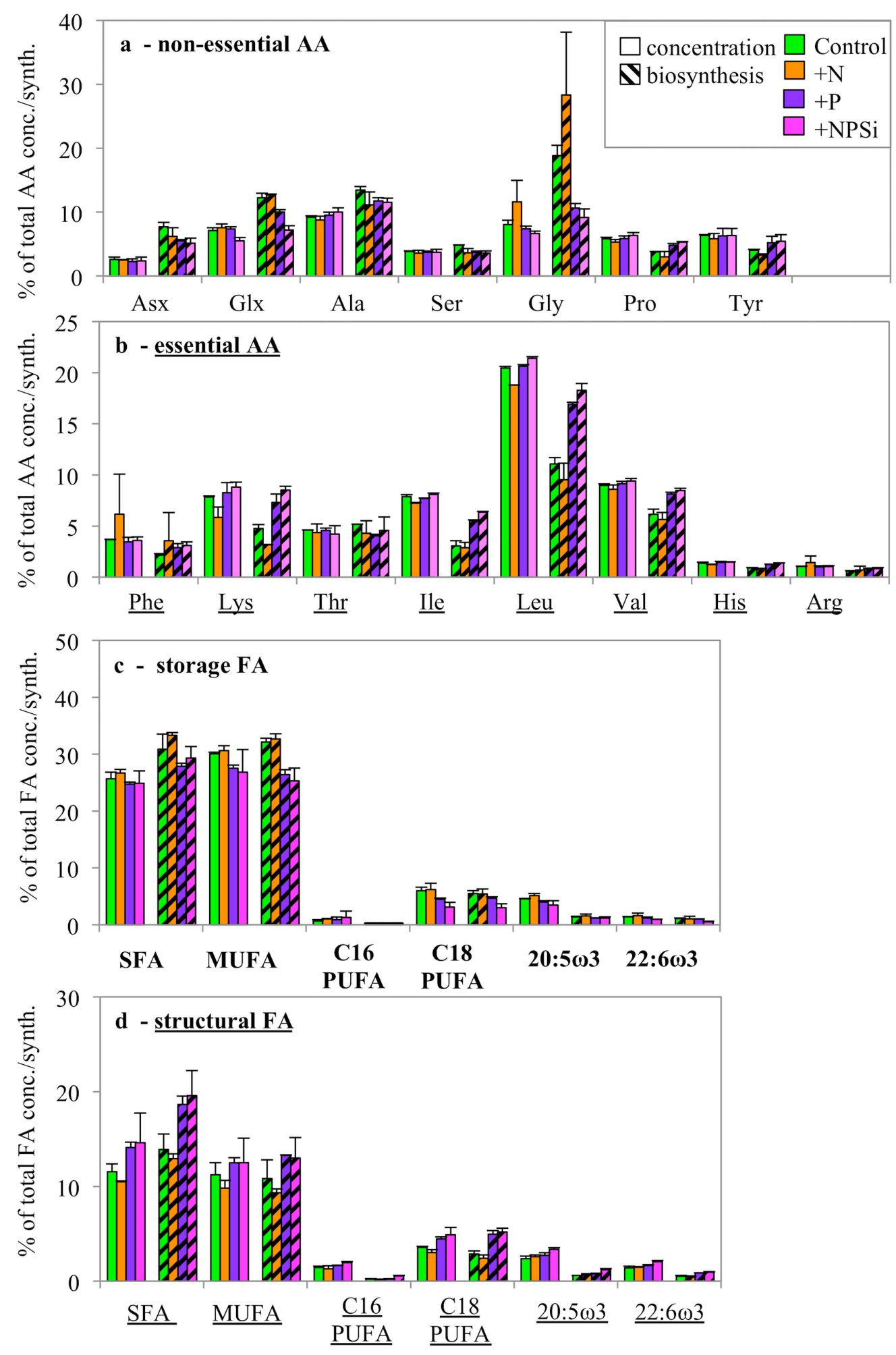

16 Fig. S2: Distribution of individual AA and FA groups in concentrations (open bars) and biosynthesis

17 (striped bars) after $72 \mathrm{~h}$ at the Coastal Station in April (Stn. 2, P/Si limited, diatom dominated). Shown are averages \pm standard deviation, $n=2$. 